\title{
Comparative proteomics analysis of peanut roots reveals differential mechanisms of cadmium detoxification and translocation between two cultivars differing in cadmium accumulation
}

\author{
Rugang Yu, Qun Jiang, Chen Xv, Lien Li, Sijia Bu and Gangrong Shi ${ }^{*}$
}

\begin{abstract}
Background: Peanut is one of the most important oil and protein crops, and it exhibits wide cultivar variations in shoot $\mathrm{Cd}$ accumulation ability. However, the mechanism of $\mathrm{Cd}$ accumulation in peanut shoots has not been well understood. In this study, the root proteomics of two cultivars differing in seed $\mathrm{Cd}$ accumulation, Fenghua 1 ( $F$, low Cd cultivar) and Silihong ( $\mathrm{S}$, high Cd cultivar), were investigated under 0 (CK) and $2 \mu \mathrm{M} \mathrm{Cd}$ conditions.

Results: A total of 4676 proteins were identified by proteomics screening. Of them, 375, 1762, 1276 and 771 proteins were identified to be differentially expressed proteins (DEPs) for comparison of $F_{C d} / F_{C K}, S_{C d} / S_{C K}, F_{C K} / S_{C K}$ and $\mathrm{F}_{\mathrm{Cd}} / \mathrm{S}_{\mathrm{Cd}}$, respectively. Silihong is more sensitive to $\mathrm{Cd}$ exposure than Fenghua 1 in terms of root proteomics. A total of 30 and 86 DEPs were identified to be related with heavy metal transport and cell wall modification, respectively. The up-regulation of $A B C B 25, A B C C 14, A B C C 2$, PDR1 and V-ATPases by $C d$ exposure in Silihong might enhance vacuolar sequestration of $\mathrm{Cd}$ and its efflux from symplast to apoplast. The higher $\mathrm{Cd}$ accumulation in the root CWs of Silihong might be resulted from its higher capability of CW modification, in which many proteins such as IRX10L, BGLU12-like, BGLU42, EXLB1, XTH30, XTH6, XYL7, PAL3, COMT, CAD1, and CCR1 were involved.
\end{abstract}

Conclusions: The vacuolar sequestration and efflux of $\mathrm{Cd}$ as well as its adsorption in $\mathrm{CW}$ might be the principal mechanism of cadmium detoxification in Silihong. The higher capacity of $\mathrm{Cd}$ accumulation and translocation of Silihong is an inherent characteristics in which ACA8 and ZIP1 might be involved.

Keywords: Peanut, Cultivar difference, Cadmium accumulation, Root proteomics

\section{Background}

Cadmium $(\mathrm{Cd})$ is one of the most toxic heavy metals that is extensively discharged into farmlands mainly by anthropogenic activities such as sewage sludge, waste incineration, and phosphate fertilizer [1]. Contamination of soil with $\mathrm{Cd}$ directly leads to its overaccumulation in the edible parts of crops, resulting in health risks to human beings through food chains. Various strategies have been applied to reduce the potential risks of $\mathrm{Cd}$ pollution to human beings [2]. Among them, screening or breeding

\footnotetext{
* Correspondence: swsgr@126.com

College of Life Sciences, Huaibei Normal University, Huaibei, Anhui 235000, People's Republic of China
}

low-Cd accumulation cultivar would be a potential way for safe food production in agriculture [3]. This is required to fully elucidate the molecular mechanisms underlying $\mathrm{Cd}$ uptake, translocation and accumulation in plants.

Peanut (Arachis hypogaea L.) is one of the most important oil crops in the world, and it is also a supplementary food due to its high nutrition. Peanut has a high Cd enrichment capacity in vegetative organs and seeds, showing a wide variation among cultivars [3-7]. The $\mathrm{Cd}$ concentration in peanut seeds mainly determined by the attenuation of $\mathrm{Cd}$ by high biomass of vegetative tissues and Cd-binding proteins in seeds $[3,5]$. It was found that seed $\mathrm{Cd}$ concentrations positively 
correlate with shoot $\mathrm{Cd}$ concentrations of seedling, suggesting that shoot $\mathrm{Cd}$ concentrations at the vegetative growth stage may be important for determining cultivar differences in $\mathrm{Cd}$ accumulation in the seed $[3,5]$. Higher proportion of $\mathrm{Cd}$ in the soluble fraction (mainly in vacuoles) was observed in the roots of low $\mathrm{Cd}$ accumulating cultivars that may contribute to low $\mathrm{Cd}$ accumulation in their shoots [8]. Additionally, Cd accumulation in peanuts was shown to associate with root morphology (i.e. high Cd cultivars have longer fine roots than low Cd cultivars) [7]. Although these studies have revealed some physiological mechanisms underlying the cultivar variation in $\mathrm{Cd}$ accumulation in peanut, the molecular mechanism has not yet been well investigated.

The accumulation of $\mathrm{Cd}$ in plant shoots is controlled by several processes such as $\mathrm{Cd}$ apoplastic influx into root tissues, cell wall adsorption, energy-driven transport to cytoplasm across membrane, vacuolar sequestration and xylem loading $[9,10]$. Most of these processes are mediated by several families of metal transporters, such as natural resistance associated macrophage proteins (Nramp) [11], zinc/iron transporters (ZIP-IRT) [12] and P1B-ATPases [13, 14]. The overexpression of plasma membrane-localized OsNramp1 in transgenic rice lines enhanced $\mathrm{Cd}$ accumulation in the shoots, which was suggested to involve in cellular Cd uptake [11]. The plasma membrane-localized OsHMA2 [13] and AtHMA4 [14] have been illustrated to be involved in xylem loading of $\mathrm{Cd}$. Cell wall $(\mathrm{CW})$ modification can alter the binding capacity of $\mathrm{Cd}$, and therefore might be responsible for the cultivar difference in root-to-shoot $\mathrm{Cd}$ translocation $[15,16]$. The pectin and hemicellulose components of the plant $\mathrm{CW}$ can offer carboxylic functional groups to join $\mathrm{Cd}^{2+}$ and limit $\mathrm{Cd}$ transport into root cell [10]. The OsPME14 [17] and AtXTH31 [18] have the ability to increase aluminium $(\mathrm{Al})$ retention in the root $\mathrm{CW}$, which may reduce the $\mathrm{Al}$ translocation to shoots. In addition, low molecular weight compounds such as glutathione (GSH), phytochelatins (PCs) and metallothioneins (MTs) have been confirmed to be involved in the vacuolar sequestration of Cd [19].

Proteomic analysis offers accurate information about molecular changes within a range of biological processes, and is a powerful tool for identifying the main regulators in the considered pathways [20]. Up to date, cultivar differences of proteomics in response to $\mathrm{Cd}$ stress have been investigated in several plant species such as amaranth [20], Sedum alfredii [21], rice [22] and soybean [23]. Some differential expressed proteins (DEPs) associated with vacuolar $\mathrm{Cd}$ sequestration, cell wall metabolism, Cd-stress defense and other processes were identified [20, 21]. In peanut, proteomics approach has been applied to address biochemical and physiological effects in response to drought stress [24].
However, little information is available on the differential responses of proteomics to $\mathrm{Cd}$ exposure between peanut cultivars.

In this study, based on isobaric tagging for relative and absolute quantification (iTRAQ), a comparative proteomics analysis was conducted on the roots of two peanut cultivars differing in seed $\mathrm{Cd}$ accumulation, Fenghua 1 (low Cd cultivar) and Silihong (high Cd cultivar). The main objectives were: (i) to assess root proteome changes in Fenghua 1 and Silihong under different $\mathrm{Cd}$ exposures; (ii) to obtain the expression and functional modes of differential expressed proteins in the roots of Fenghua 1 and Silihong under different Cd exposures; and (iii) to elucidate the crucial processes that are responsible for the difference in $\mathrm{Cd}$ accumulation between the two cultivars. The results obtained from the present study would contribute to understanding the molecular mechanism of cultivar variation in $\mathrm{Cd}$ accumulation of peanuts and provide valuable information for screening or breeding of low Cd cultivars.

\section{Results \\ Cd accumulation and translocation in two peanut cultivars}

$\mathrm{Cd}$ concentrations in roots and shoots as well as translocation factors of $\mathrm{Cd}$ from the roots to shoots differed between the two cultivars tested, and were significantly affected by $\mathrm{Cd}$ treatments as well as $\mathrm{Cd} \times$ cultivar interactions (Fig. 1). Cd concentrations in roots and shoots increased with increasing $\mathrm{Cd}$ concentrations in the nutrition solutions (Fig. 1a and b), while translocation factors were highest in the $2 \mu \mathrm{M} \mathrm{Cd}$ treatment for both cultivars (Fig. 1c). By contrast, Silihong showed higher shoot $\mathrm{Cd}$ concentrations and IFs than Fenghua 1 in all $\mathrm{Cd}$ treatments (Fig. $1 \mathrm{~b}$ and $\mathrm{c}$ ). $\mathrm{Cd}$ concentrations in roots were also observed to be higher in Silihong than in Fenghua 1, depending on Cd treatments (Fig. 1a). The data presented here, concurred with our previous results [5], suggesting that Fenghua 1 has a lower capacity for $\mathrm{Cd}$ translocation and accumulation than Silihong.

\section{$\mathrm{Cd}$, total sugar and uronic acid in root CW components of Fenghua 1 and Silihong}

The two cultivars differed from each other in $\mathrm{Cd}$ concentrations and contents of total sugar and uronic acid in the $\mathrm{CW}$ composition (Fig. 2). When plants were exposed to $2 \mu \mathrm{M} \mathrm{Cd}$, Silihong had higher Cd concentrations in the CW as well as in the hemicelluloses ( $\mathrm{HC} 1$ and $\mathrm{HC} 2$ ) and cellulose than Fenghua 1, whereas $\mathrm{Cd}$ concentrations in the pectin were higher in Fenghua 1 than in Silihong (Fig. 2a). In the $\mathrm{CW}$, most $\mathrm{Cd}$ was bound to the hemicelluloses, accounting for 57 and $61 \%$ for Fenghua 1 and Silihong respectively. Cd exposure significantly increased the uronic acid content in the 


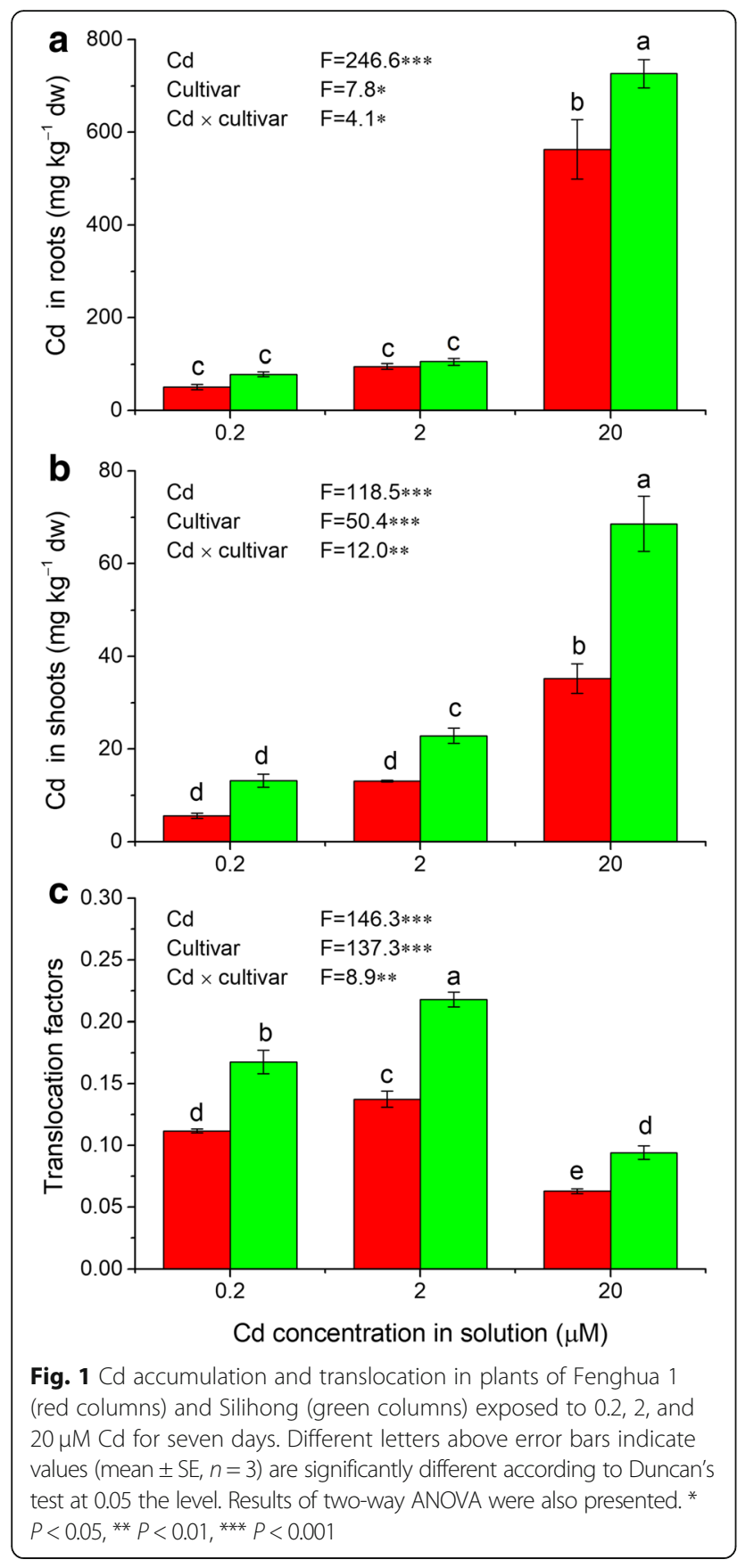

$\mathrm{CW}$ and its pectin and $\mathrm{HC} 2$ components in Fenghua 1, while in Silihong, $\mathrm{Cd}$ enhanced the uronic acid content in the $\mathrm{HC} 2$ and cellulose (Fig. 2b). $\mathrm{Cd}$ did not change the total sugar content in the $\mathrm{CW}$ and its pectin component for both cultivars (Fig. 2c). The total sugar content of the hemicelluloses ( $\mathrm{HC} 1$ and $\mathrm{HC} 2)$ and cellulose was increased by $\mathrm{Cd}$ treatments in Silihong, while they remained unaffected in Fenghua 1 (Fig. 2c). Under Cd exposure, Silihong showed a higher uronic acid content in the $\mathrm{HC} 2$ and cellulose and a higher total sugar content in the $\mathrm{CW}$ and its hemicelluloses ( $\mathrm{HC} 1$ and $\mathrm{HC} 2)$

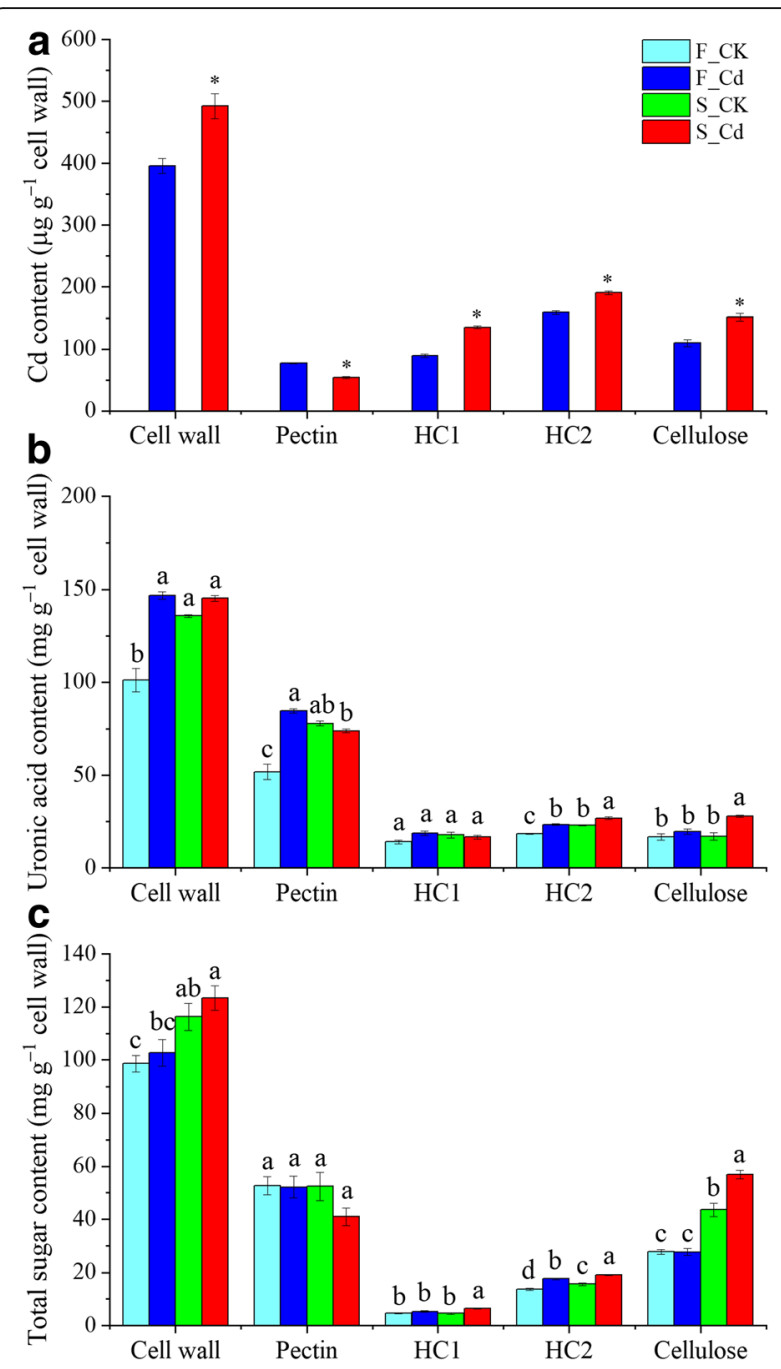

Fig. $\mathbf{2} \mathrm{Cd}$ accumulation (a) and the content of uronic acid (b) and total sugar $(\mathbf{c})$ in the cell wall and its components. Asterisk $\left(^{*}\right)$ above error bars indicate values (mean $\pm \mathrm{SE}, n=4$ ) are significantly different between Fenghua 1 and Silihong according to independent-samples t-test at 0.05 the level. Different letters indicate values are significantly different according to Duncan's test at 0.05 the level

and cellulose components than Fenghua 1, whereas Fenghua 1 had higher uronic acid contents in the pectin than Silihong (Fig. 2, b and c).

\section{Overview of protein identified in Fenghua 1 and Silihong} A total of 307,137 MS/MS spectra from the eight tested samples (two replicates $\times$ two species $\times$ two treatments) were identified, in which 62,850 spectra were matched with the known spectra (Fig. 3a). Among them, 52,728 unique spectra were matched to 15,343 unique peptides, and 4676 proteins were successfully identified with the cutoff Mascot Percolator FDR $\leq 0.01$. The number of proteins with a single peptide, $2-5$ peptides, $6-10$ peptides and $>11$ peptides were 1897, 2006, 563 and 210, 


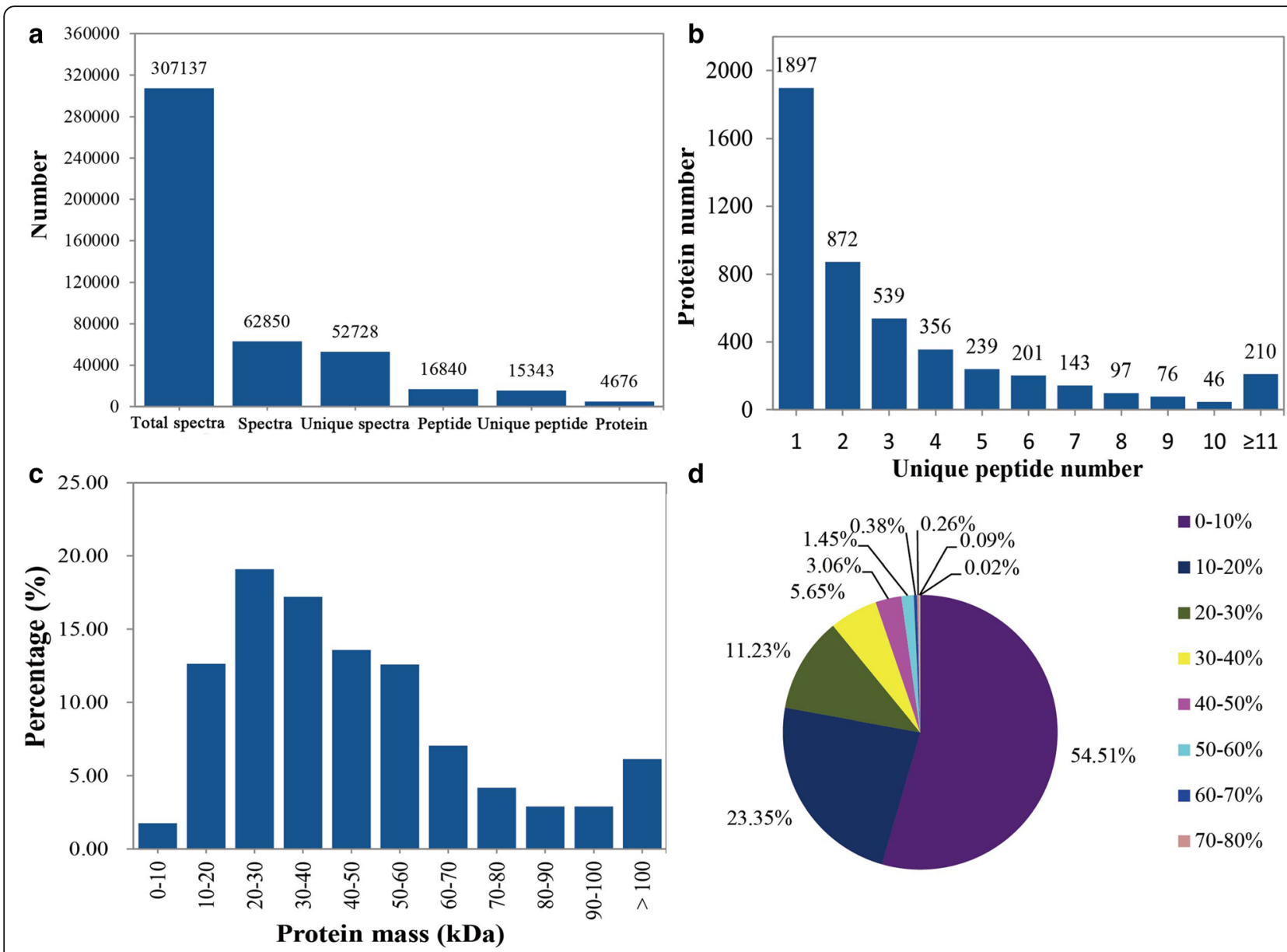

Fig. 3 Summary of iTRAQ results. (a) total spectra, matched spectra, matched peptides, unique peptides, and identified proteins; (b) Number of peptides associated with identified proteins; (c) protein relative molecular mass distribution; (d) sequence coverage for identified proteins

respectively (Fig. 3b). The majority of identified protein masses distributed from 11 to $100 \mathrm{kDa}$ with good average coverage. Among them, $11-50 \mathrm{kDa}$ covered $62.53 \%, 51-100 \mathrm{kDa}$ made up $29.58 \%$, and $>100 \mathrm{kDa}$ comprised $6.14 \%$ of the proteins (Fig. 3c). The identified proteins with peptide coverage more than 10 and $20 \%$ are 2127 and 1035, accounting for 45.49 and $22.13 \%$ respectively (Fig. 3d). The repeatability analysis based on coefficient of variation (CV) was shown in Additional file 1: Figure S1. The lower CV of replicates in the same treatment $(0.056-0.086)$ than that of different treatments $(0.10-0.13)$ indicates a good reproducibility of the data in this study.

\section{Identification of differentially expressed proteins (DEPs)}

Based on the standard that Bonferroni-corrected $P$-value $<0.05$ and fold changes $>1.2$ or $<0.833$, a total of 2669 DEPs were identified in the four comparisons (Additional file 2: Table S1). Among them, 375 and 1762 proteins were Cd-responsive DEPs for Fenghua 1 and Silihong, respectively. Cd exposure up-regulated 166 and
1314 proteins for Fenghua 1 and Silihong, respectively, whereas 209 and 448 proteins in the roots of Fenghua 1 and Silihong were down-regulated by Cd (Fig. 4a). Two cultivars share 78 up- and 52 down-regulated Cd-responsive DEPs (Fig. 4b and c). In the control, 1276 DEPs (875 up- and 401 down-regulated proteins) were identified between the two cultivars, while in the $\mathrm{Cd}$ treatment, 771 DEPs (255 up- and 516 down-regulated proteins) were identified (Fig. 4a). Regardless of Cd exposure, the abundance of 120 proteins was higher in Fenghua 1 than in Silihong, while those of 58 proteins were higher in Silihong than in Fenghua 1 (Fig. 4b and c).

GO and KEGG pathway enrichment analysis of the DEPs A total of 63, 171, 47 and 200 enriched GO terms $(P$-value $<0.05)$ were obtained from $\mathrm{F}_{\mathrm{Cd}} / \mathrm{F}_{\mathrm{CK}}, \mathrm{S}_{\mathrm{Cd}} / \mathrm{S}_{\mathrm{CK}}$, $\mathrm{F}_{\mathrm{CK}} / \mathrm{S}_{\mathrm{CK}}$ and $\mathrm{F}_{\mathrm{Cd}} / \mathrm{S}_{\mathrm{Cd}}$, respectively, which represent three categories (cellular component, molecular function and biological process) (Additional file 3: Table S2). The most enriched GO terms $(P$-value $<0.01)$ were listed in 


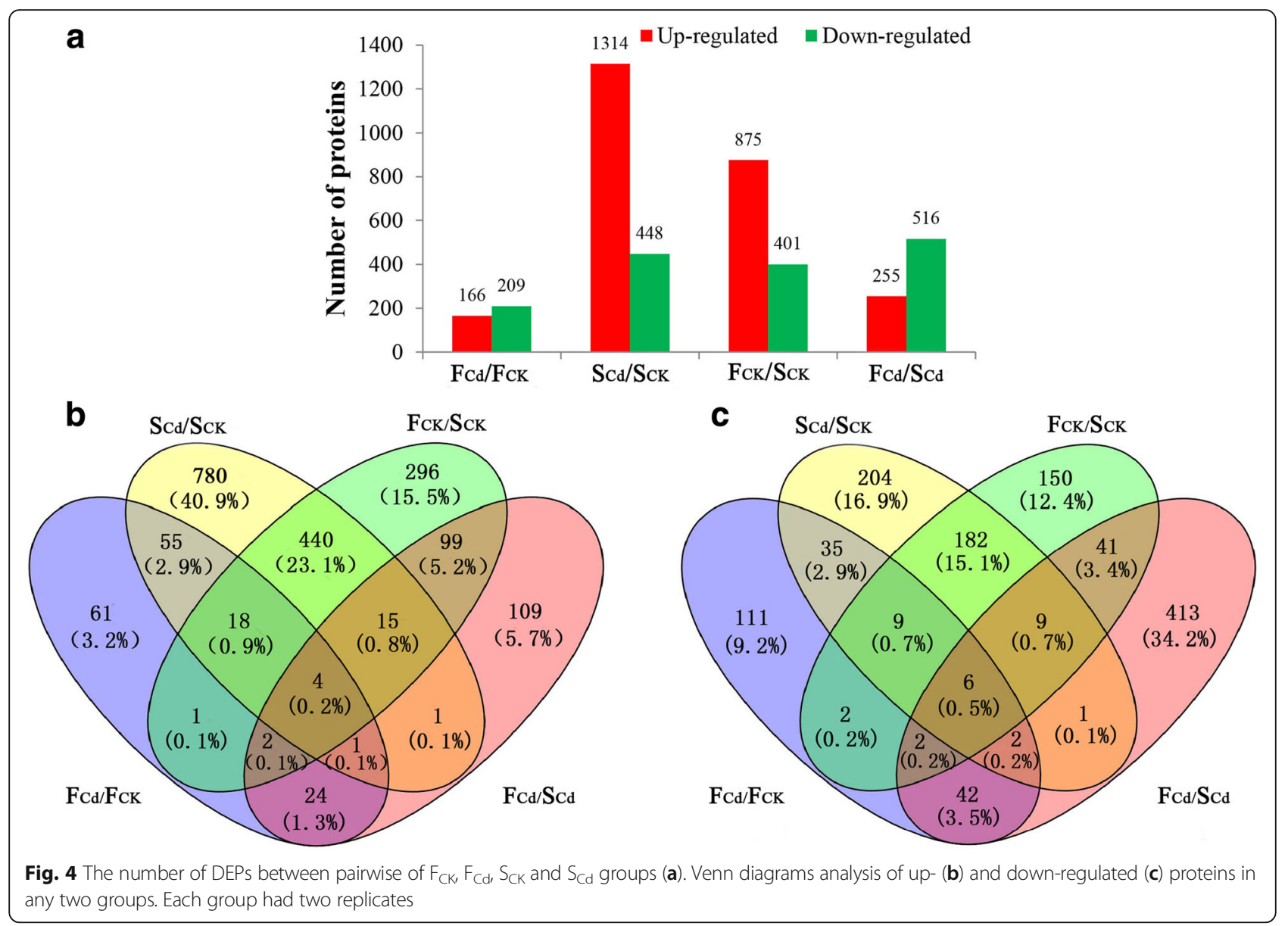

Additional file 4: Table S3. For Silihong, the most enriched GO terms of Cd-responsive DEPs include two subcategories of cellular component (nucleus and phragmoplast), 17 subcategories of molecular function (i.e. heterocyclic compound binding, organic cyclic compound binding, etc.), and 15 subcategories of biological process (i.e. cellular process, cellular metabolic process, etc). Cd-responsive DEPs of Fenghua 1 were assigned to molecular function (i.e. glutathione transferase activity) and biological processes (i.e. response to stress, response to oxidative stress) (Additional file 4: Table S3). For DEPs between Fenghua 1 and Silihong, 11 GO terms of cellular component (i.e. plastid, chloroplast and cell wall), 22 GO terms of molecular function (catalytic activity, ion binding, organic cyclic compound binding and cation binding), and $47 \mathrm{GO}$ terms of biological process (metabolic process, response to cadmium ion, response to metal ion and organic acid metabolic process) were most enriched under $\mathrm{Cd}$ exposure (Additional file 4: Table S3).

With $P$-value $<0.05$ as the cutoff, a total of 7, 8, 5 and 16 significantly enriched pathways were identified in $\mathrm{F}_{\mathrm{Cd}} / \mathrm{F}_{\mathrm{CK}}, \mathrm{S}_{\mathrm{Cd}} / \mathrm{S}_{\mathrm{CK}}, \mathrm{F}_{\mathrm{CK}} / \mathrm{S}_{\mathrm{CK}}$ and $\mathrm{F}_{\mathrm{Cd}} / \mathrm{S}_{\mathrm{Cd}}$, respectively (Table 1). For Cd-responsive DEPs, the top two significantly enriched pathways were 'phenylpropanoid biosynthesis' [ko00940] and 'Glutathione metabolism' [ko00480] in Fenghua 1, and 'Spliceosome' [ko03040] and 'Pyruvate metabolism' [ko00620] in Silihong. Moreover, only one pathway, 'glutathione metabolism, was significantly enriched in both cultivars. For DEPs between Fenghua 1 and Silihong under $\mathrm{Cd}$ exposure, the most predominant pathways were 'metabolic pathway' [ko01100], 'biosynthesis of secondary metabolites' [ko01110], 'Carbon metabolism' [ko01200], 'phenylpropanoid biosynthesis' and 'biosynthesis of amino acids' [ko01230].

\section{DEPs related to heavy metal transport}

A total of 79 DEPs were identified to have homology with various transporters (Additional file 5: Table S4). Among them, 30 DEPs were identified to be related with heavy metal transport, including ATP-binding cassette $(\mathrm{ABC})$ transporters, zinc transporter (ZIP1), metal tolerance protein (e.g. MTPc2 and MTPc4), oligopeptide transporter 7 (OPT7), pleiotropic drug resistance protein 1 (PDR1), V-type proton ATPase (V-ATPase), endoplasmic reticulum-type calcium-transporting ATPase 4 (ECA4) and plasma membrane-type calcium-transporting ATPase 
Table 1 Significantly enriched KEGG pathways for the DEPS

\begin{tabular}{|c|c|c|c|c|c|c|c|c|c|}
\hline \multirow[t]{2}{*}{ Pathway } & \multicolumn{4}{|c|}{ Sample number } & \multicolumn{4}{|l|}{$P$-value } & \multirow{2}{*}{$\begin{array}{l}\text { Pathway } \\
\text { ID }\end{array}$} \\
\hline & $\mathrm{F}_{\mathrm{Cd}} / \mathrm{F}_{\mathrm{CK}}$ & $\mathrm{S}_{\mathrm{Cd}} / \mathrm{S}_{\mathrm{CK}}$ & $\mathrm{F}_{\mathrm{CK}} / \mathrm{S}_{\mathrm{CK}}$ & $\mathrm{F}_{\mathrm{Cd}} / \mathrm{S}_{\mathrm{Cd}}$ & $\mathrm{F}_{\mathrm{Cd}} / \mathrm{F}_{\mathrm{CK}}$ & $\mathrm{S}_{\mathrm{Cd}} / \mathrm{S}_{\mathrm{CK}}$ & $\mathrm{F}_{\mathrm{CK}} / \mathrm{S}_{\mathrm{CK}}$ & $\mathrm{F}_{\mathrm{Cd}} / \mathrm{S}_{\mathrm{Cd}}$ & \\
\hline Glutathione metabolism & 11 & 35 & 13 & 19 & 0.0156 & 0.0239 & 0.9609 & 0.0178 & ko00480 \\
\hline Phenylpropanoid biosynthesis & 20 & 55 & 55 & 53 & 0.0085 & 0.6295 & 0.0038 & 0.0000 & ko00940 \\
\hline Carotenoid biosynthesis & 6 & 13 & 5 & 2 & 0.0125 & 0.1544 & 0.8753 & 0.9500 & ko00906 \\
\hline Phosphatidylinositol signaling system & 5 & 7 & 6 & 2 & 0.0158 & 0.7016 & 0.4729 & 0.8767 & ko04070 \\
\hline Photosynthesis & 6 & 5 & 4 & 6 & 0.0248 & 0.9975 & 0.9796 & 0.3996 & ko00195 \\
\hline Inositol phosphate metabolism & 6 & 6 & 6 & 4 & 0.0381 & 0.9967 & 0.9193 & 0.8351 & ko00562 \\
\hline Cutin, suberine and wax biosynthesis & 3 & 3 & 2 & 2 & 0.0474 & 0.8587 & 0.8450 & 0.5795 & ko00073 \\
\hline Spliceosome & 8 & 55 & 40 & 13 & 0.5496 & 0.0012 & 0.0062 & 0.9105 & ko03040 \\
\hline Benzoxazinoid biosynthesis & 1 & 5 & 1 & 4 & 0.3833 & 0.0340 & 0.8515 & 0.0092 & ko00402 \\
\hline Terpenoid backbone biosynthesis & 1 & 18 & 6 & 10 & 0.9184 & 0.0203 & 0.8861 & 0.0271 & ko00900 \\
\hline Stilbenoid, diarylheptanoid and gingerol biosynthesis & 2 & 9 & 6 & 4 & 0.2070 & 0.0042 & 0.0505 & 0.1001 & ko00945 \\
\hline Ribosome biogenesis in eukaryotes & 1 & 16 & 8 & 6 & 0.8560 & 0.0046 & 0.3181 & 0.2100 & ko03008 \\
\hline Citrate cycle (TCA cycle) & 1 & 24 & 4 & 9 & 0.9759 & 0.0390 & 0.9996 & 0.3754 & ko00020 \\
\hline Pyruvate metabolism & 2 & 38 & 10 & 17 & 0.9855 & 0.0314 & 0.9993 & 0.1453 & ko00620 \\
\hline Mismatch repair & 1 & 7 & 7 & 1 & 0.6199 & 0.1311 & 0.0226 & 0.8926 & ko03430 \\
\hline Plant-pathogen interaction & 6 & 38 & 31 & 18 & 0.6645 & 0.1578 & 0.0437 & 0.1951 & ko04626 \\
\hline Photosynthesis - antenna proteins & - & 5 & 5 & 1 & - & 0.0814 & 0.0187 & 0.7277 & ko00196 \\
\hline Biosynthesis of secondary metabolites & 66 & 279 & 173 & 175 & 0.0811 & 0.5340 & 0.9913 & 0.0000 & ko01110 \\
\hline Metabolic pathways & 101 & 446 & 293 & 271 & 0.2113 & 0.9448 & 0.9988 & 0.0000 & ko01100 \\
\hline Alanine, aspartate and glutamate metabolism & 4 & 13 & 6 & 13 & 0.2843 & 0.6237 & 0.9438 & 0.0033 & ko00250 \\
\hline Cyanoamino acid metabolism & 4 & 8 & 11 & 12 & 0.3746 & 0.9964 & 0.5438 & 0.0288 & ko00460 \\
\hline Carbon fixation in photosynthetic organisms & 5 & 17 & 12 & 17 & 0.4541 & 0.9323 & 0.8876 & 0.0109 & ko00710 \\
\hline Nitrogen metabolism & 2 & 8 & 7 & 8 & 0.4914 & 0.5933 & 0.3383 & 0.0169 & ko00910 \\
\hline Pentose phosphate pathway & 4 & 17 & 14 & 17 & 0.5801 & 0.8401 & 0.5716 & 0.0039 & ko00030 \\
\hline Aminoacyl-tRNA biosynthesis & 3 & 18 & 10 & 16 & 0.7672 & 0.7244 & 0.9212 & 0.0079 & ko00970 \\
\hline Biosynthesis of amino acids & 12 & 75 & 28 & 51 & 0.7999 & 0.3595 & 1.0000 & 0.0002 & ko01230 \\
\hline Carbon metabolism & 11 & 81 & 37 & 53 & 0.9429 & 0.5059 & 0.9997 & 0.0011 & ko01200 \\
\hline One carbon pool by folate & - & 7 & 2 & 7 & - & 0.6400 & 0.9808 & 0.0302 & ko00670 \\
\hline Arginine and proline metabolism & - & 11 & 3 & 10 & - & 0.7399 & 0.9969 & 0.0337 & ko00330 \\
\hline
\end{tabular}

8 (ACA8) (Table 2). Most of heavy metal transporters (20 proteins) were altered by $\mathrm{Cd}$ exposure in Silihong, including 15 up-regulated proteins (ABCB11, ABCB25, ABCC4, ABCC2, ABCC14, ABCG8-like, ABCF1, ABCF3, ECA4, MTP2, PAA1, V-ATPase subunit H, V-ATPase subunit d2, $\mathrm{V}$-ATPase subunit $\mathrm{H}$ isoform $\mathrm{X} 3$ ) and 5 down-regulated proteins (ATX1, ZIP1, ACA8, V-ATPase subunit D). In contrast, only two heavy metal transporters were identified to be Cd-responsive DEPs in Fenghua 1, including a up-regulated protein (ABCG8) and a down-regulated protein (OPT7) (Table 2). Under Cd exposure, 11 heavy metal transporters (ABCB11, ABCB25, ABCC14, PDR1, ECA4, PAA1, MTPc2, MTPc4, V-ATPase catalytic subunit A) showed higher expression in Silihong than in Fenghua, while V-ATPase subunit G and V-ATPase $16 \mathrm{kDa}$ proteolipid subunit isoform $\mathrm{X} 4$ were lower in Silihong than in
Fenghua. All these proteins were not DEPs of the two cultivars in the absence of $\mathrm{Cd}$ (Table 2).

\section{DEPs related to cell wall modification}

Totally, 86 DEPs involved in CW modification were identified, including 66 proteins related to the CW degradation, 14 proteins related to $\mathrm{CW}$ synthesis and six expansin proteins (EPs) (Additional file 6: Table S5). Cd increased the abundance of 11 proteins belonging to pectinesterase/pectinesterase inhibitors (PPE8B-like, PPE51), xyloglucan endotransglucosylase/hydrolase proteins (XTH1, XTH23), cytochrome P450, beta-glucosidase (GLUC45), endoglucanase 9 (EG9), pectin acetylesterase (PAE3), pectinesterase (PE2), endochitinase and glucan endo-1,3-beta-glucosidase (XP_015952748.1), but decreased that of casparian strip membrane protein 2, glucan endo-1,3-beta-glucosidase 
Table 2 DEPs involved in metal transport in roots of the two peanut cultivars

\begin{tabular}{|c|c|c|c|c|c|c|}
\hline \multirow[t]{2}{*}{ Protein ID } & \multirow[t]{2}{*}{ Protein name } & \multirow[t]{2}{*}{ Abbr. } & \multicolumn{4}{|c|}{ Mean Ratio } \\
\hline & & & $\mathrm{F}_{\mathrm{Cd}} / \mathrm{F}_{\mathrm{CK}}$ & $\mathrm{S}_{\mathrm{Cd}} / \mathrm{S}_{\mathrm{CK}}$ & $\mathrm{F}_{\mathrm{CK}} / \mathrm{S}_{\mathrm{CK}}$ & $\mathrm{F}_{\mathrm{Cd}} / \mathrm{S}_{\mathrm{Cd}}$ \\
\hline XP_015967663.1 & $\mathrm{ABC}$ transporter $\mathrm{A}$ family member 2 & ABCA2 & 0.85 & 1.10 & $1.28^{*}$ & 0.91 \\
\hline XP_015967661.1 & $\mathrm{ABC}$ transporter $\mathrm{A}$ family member 7 isoform $\mathrm{X} 2$ & ABCA7 & 0.86 & 1.12 & $1.22^{*}$ & 0.94 \\
\hline XP_020982984.1 & ABC transporter B family member 11 & $\mathrm{ABCB} 11$ & 1.01 & $1.79^{*}$ & 1.00 & $0.57^{*}$ \\
\hline XP_015939460.1 & ABC transporter B family member 11 & $\mathrm{ABCB} 11$ & 1.12 & $1.71^{*}$ & 1.16 & $0.81^{*}$ \\
\hline XP_015931717.1 & ABC transporter B family member 25 , mitochondrial & ABCB25 & 0.98 & $1.38^{*}$ & 1.11 & $0.80^{*}$ \\
\hline XP_015959705.1 & $\mathrm{ABC}$ transporter $\mathrm{C}$ family member 14 & $\mathrm{ABCC} 14$ & 1.01 & $1.65^{*}$ & 1.17 & $0.72^{*}$ \\
\hline XP_015942829.1 & $\mathrm{ABC}$ transporter $\mathrm{C}$ family member 2-like & $\mathrm{ABCC} 2$ & 0.96 & $1.27^{*}$ & 1.17 & 0.87 \\
\hline XP_015951104.1 & $\mathrm{ABC}$ transporter $\mathrm{C}$ family member 4 & $\mathrm{ABCC} 4$ & 0.94 & $1.34^{*}$ & $1.25^{*}$ & 0.86 \\
\hline XP_015935759.1 & $\mathrm{ABC}$ transporter $\mathrm{F}$ family member 1 & $\mathrm{ABCF} 1$ & 1.05 & $1.51^{*}$ & $1.24^{*}$ & 0.90 \\
\hline XP_015938024.1 & ABC transporter $\mathrm{F}$ family member 3 & ABCF3 & 1.02 & $1.33^{*}$ & 1.15 & 0.89 \\
\hline XP_020986785.1 & ABC transporter G family member 8-like & ABCG8 & $1.30^{*}$ & $1.48^{*}$ & 1.03 & 0.92 \\
\hline XP_015969915.1 & calcium-transporting ATPase 4, endoplasmic reticulum-type & $\mathrm{Ca}^{2+}$-ATPase4 & 1.12 & $1.69^{*}$ & 1.11 & $0.76^{*}$ \\
\hline XP_020993898.1 & calcium-transporting ATPase 8, plasma membrane isoform X6 & $\mathrm{Ca}^{2+}$-ATPase 8 & 1.43 & $0.74^{*}$ & $0.65^{*}$ & 1.26 \\
\hline XP_015941278.1 & copper transport protein ATX1 & ATX1 & 0.79 & $0.64^{*}$ & $0.72^{*}$ & 0.89 \\
\hline XP_015949536.1 & copper transport protein ATX1 & ATX1 & 1.05 & $0.79^{*}$ & $0.74^{*}$ & 1.02 \\
\hline XP_015943398.1 & copper-transporting ATPase PAA1, chloroplastic & PAA1 & 1.02 & $1.24^{*}$ & 1.00 & $0.81^{*}$ \\
\hline XP_015951091.1 & metal tolerance protein 2 isoform $\times 2$ & MTP2 & 1.61 & $2.19^{*}$ & $0.68^{*}$ & 0.54 \\
\hline XP_015969432.1 & metal tolerance protein $\mathrm{C} 2$ & MTPC2 & 0.80 & 1.22 & 1.24 & $0.80^{*}$ \\
\hline XP_015938018.1 & metal tolerance protein $\mathrm{C} 4$ & MTPc4 & 0.84 & 1.18 & 1.07 & $0.77^{*}$ \\
\hline XP_015951854.1 & oligopeptide transporter 7 & OPT7 & $0.77^{*}$ & 0.94 & 1.13 & 0.91 \\
\hline XP_015937455.1 & pleiotropic drug resistance protein 1 & PDR1 & 0.89 & 1.28 & 1.05 & $0.75^{*}$ \\
\hline XP_020983616.1 & V-type proton ATPase $16 \mathrm{kDa}$ proteolipid subunit isoform $\mathrm{X} 4$ & V-ATPase X4 & 1.00 & 0.88 & 1.16 & $1.28^{*}$ \\
\hline XP_015958526.1 & V-type proton ATPase catalytic subunit A & V-ATPase subunit A & 1.00 & 1.19 & 0.95 & $0.80^{*}$ \\
\hline XP_015960547.1 & V-type proton ATPase subunit D & V-ATPase subunit D & 1.09 & $0.82^{*}$ & $0.83^{*}$ & 1.07 \\
\hline XP_015962803.1 & V-type proton ATPase subunit $\mathrm{d} 2$ & V-ATPase subunit $\mathrm{d} 2$ & 1.01 & $1.41^{*}$ & 1.09 & $0.81^{*}$ \\
\hline XP_020999809.1 & V-type proton ATPase subunit F & V-ATPase subunit F & 0.92 & 1.23 & $1.33^{*}$ & 1.02 \\
\hline XP_020986386.1 & V-type proton ATPase subunit $G$ & V-ATPase subunit $G$ & 1.05 & 0.86 & 1.04 & $1.27^{*}$ \\
\hline XP_015964081.1 & V-type proton ATPase subunit $\mathrm{H}$ & V-ATPase subunit H & 1.04 & $1.33^{*}$ & 1.04 & 0.85 \\
\hline XP_015948413.1 & V-type proton ATPase subunit $\mathrm{H}$ isoform $\mathrm{X} 3$ & V-ATPase subunit HX3 & 1.07 & $1.44^{*}$ & 1.16 & 0.89 \\
\hline XP_020984784.1 & zinc transporter 1 & ZIP1 & 0.97 & $0.78^{*}$ & $0.73^{*}$ & 0.91 \\
\hline
\end{tabular}

* indicate the protein is differentially expressed in the pairwise comparison

(XP_015969184.1), PE (XP_020993886.1), expansin-like B1, and XTH22 in Fenghua 1. In Silihong, 32 proteins belonging to GLUCs, EGs, XTHs, P450, PEs, PPE, expansins, beta-galactosidase ( $\beta$-Gal), polygalacturonases (PGs), pectate lyases (PLs), phospholipase A-2-activating proteins (PLAP), beta-1,4-xylosyltransferase (IRX10L), and endo-1,3;1,4-beta-D-glucanase were up-regulated by $\mathrm{Cd}$ exposure, and 12 proteins belonging to XTHs, GLUCs, PEs, P450, PPEs, casparian strip membrane protein 2, chitinase-3-like protein, and expansin-like were down-regulated by $\mathrm{Cd}$ exposure. Under $\mathrm{Cd}$ exposure, a total of 41 DEPs were identified between the two cultivars. Among them, 31 were found to highly expressed in Fenghua 1 compared with Silihong, while the other ten proteins were lower in Fenghua 1 than Silihong regarding the abundance. Regardless of Cd exposure, 13 proteins including four glucan endo-1,3-beta-glucosidase, three polygalacturonase, as well as $\mathrm{PE}, \beta$-Gal, XTH31, polygalacturonase inhibitor 2 (PGIP2), beta-xylosidase/alpha-L-arabinofuranosidase 2 (XLA2), and endo-1,3;1,4-beta-D-glucanase-like, were higher in abundance in Fenghua 1 than in Silihong, whereas the abundance of four proteins (chitinase-3-like protein 1, expansin-like B1, beta-galactosidase isoform X2 and beta-glucosidase 12-like) were lower in Fenghua 1 than Silihong.

A total of 64 DEPs were identified to be involved in lignin biosynthesis (Additional file 7: Table S6). Compared with the control, $\mathrm{Cd}$ exposure up-regulated 8 and 
16 proteins for Fenghua 1 and Silihong respectively, while five proteins in Fenghua 1 and 16 proteins in Silihong were down-regulated by $\mathrm{Cd}$. Under $\mathrm{Cd}$ exposure, 26 proteins belonging to peroxidases (PODs), laccases (LACs) and caffeoyl-CoA O-methyltransferase (CCoAOMT) were more abundant in Fenghua 1 than in Silihong, while only five proteins (LAC3, CCR2, 4CL2, HCT, PAL3) were higher in Silihong than in Fenghua 1 (Additional file 7: Table S6).

\section{Verification of iTRAQ data by RT-qPCR}

To validate the iTRAQ results, the transcriptional analysis of 11 candidate DEPs was performed using RT-qPCR (Fig. 5). The expression level of 11, 10, 8 and 7 genes showed the same or similar trend of change with their corresponding protein abundance in $\mathrm{F}_{\mathrm{Cd}} / \mathrm{S}_{\mathrm{Cd}}, \mathrm{S}_{\mathrm{Cd}} /$ $\mathrm{S}_{\mathrm{CK}}, \mathrm{F}_{\mathrm{CK}} / \mathrm{S}_{\mathrm{CK}}$ and $\mathrm{F}_{\mathrm{Cd}} / \mathrm{F}_{\mathrm{CK}}$, respectively (Fig. 5; Additional file 2: Table S1). These results suggested that the majority of proteins were regulated directly at the transcription level. However, four genes encoding peroxidase A2 $\left(\mathrm{F}_{\mathrm{CK}} / \mathrm{S}_{\mathrm{CK}}\right)$, pectinesterase and pleiotropic drug resistance protein $1\left(\mathrm{~F}_{\mathrm{Cd}} / \mathrm{F}_{\mathrm{CK}}, \mathrm{F}_{\mathrm{CK}} / \mathrm{S}_{\mathrm{CK}}\right)$ and metal tolerance protein $\mathrm{C} 2\left(\mathrm{~F}_{\mathrm{Cd}} / \mathrm{F}_{\mathrm{CK}}\right)$, indicated an inconsistent relationship between the patterns of mRNA expression and protein abundance (Fig. 5; Additional file 2: Table S1). For instance, the peroxidase A2 was down-regulated at the transcription level in $\mathrm{F}_{\mathrm{CK}} / \mathrm{S}_{\mathrm{CK}}$, whereas it was obviously up-regulated at the protein level. The pectinesterase and pleiotropic drug resistance protein 1 showed opposing expression pattern in $\mathrm{F}_{\mathrm{Cd}} / \mathrm{F}_{\mathrm{CK}}$ at mRNA levels and their corresponding protein abundance. These paradoxical discrepancies between RT-qPCR and iTRAQ proteomics might attribute to the sensitivity between two analysis methods and a difference between the processes of mRNA translation and posttranslational modifications.

\section{Discussion}

Differential responses of proteomic profiles to $\mathrm{Cd}$ between Fenghua 1 and Silihong

Proteome studies have been successfully and increasingly used for revealing the mechanism of $\mathrm{Cd}$ resistance and accumulation in some plant species [20, 22, 23]. To elucidate the mechanisms involved in cultivar differences in $\mathrm{Cd}$ accumulation in peanuts, root proteomic profiles of Fenghua 1 and Silihong were analysed under control and Cd-treated conditions by an iTRAQ-based quantitative proteomics approach. Totally 4676 proteins were identified in this study, from which 375, 1762, 1276 and 771 proteins exhibited significant differential abundance in $\mathrm{F}_{\mathrm{Cd}} / \mathrm{F}_{\mathrm{CK}}, \mathrm{S}_{\mathrm{Cd}} / \mathrm{S}_{\mathrm{CK}}, \mathrm{F}_{\mathrm{CK}} / \mathrm{S}_{\mathrm{CK}}$ and $\mathrm{F}_{\mathrm{Cd}} / \mathrm{S}_{\mathrm{Cd}}$ comparison, respectively (Additional file 2: Table S1). Cd induced 375 DEPs in the roots of Fenghua 1, whereas 1762 proteins

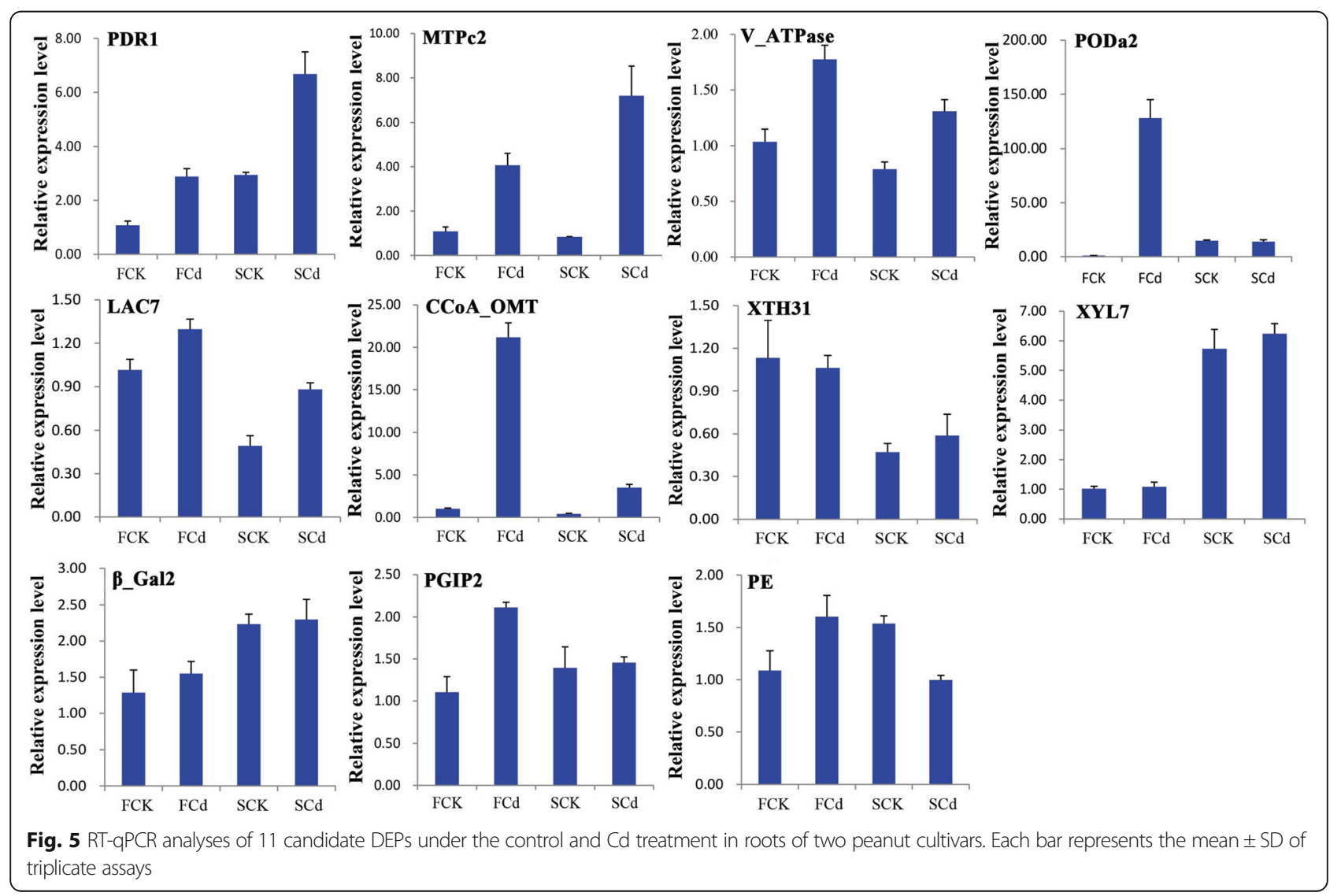


were identified between 0 and $2 \mu \mathrm{M}$ Cd treatments in Silihong, which was 3.7-fold higher than those of Fenghua 1 (Fig. 4a). Between the two cultivars, most of DEPs $(68.7 \%)$ showed higher abundance in Fenghua 1 in the absence of $\mathrm{Cd}$, while in the presence of $\mathrm{Cd}$, most of DEPs (67\%) were higher in Silihong (Fig. 4a). These results suggest that the two cultivars differed in the molecular mechanisms in response to $\mathrm{Cd}$ exposure. Silihong is more sensitive to $\mathrm{Cd}$ exposure than Fenghua 1 in terms of root proteomics.

\section{Transporters involved in Cd uptake and translocation in Fenghua 1 and Silihong}

Transport of $\mathrm{Cd}^{2+}$ across the membrane system in plant cells has been shown to be mediated by transports of divalent ions such as $\mathrm{Zn}^{2+}, \mathrm{Ca}^{2+}, \mathrm{Fe}^{2+}, \mathrm{Mn}^{2+}, \mathrm{Cu}^{2+}$ and $\mathrm{Mg}^{2+}$ [9]. However, this is varied among plant species or among cultivars/ecotypes within a species, and little is known about the mechanism of $\mathrm{Cd}$ uptake and translocation in peanut plants. In the current study, we found that Silihong shows higher shoot $\mathrm{Cd}$ concentration and higher translocation factors than Fenghua 1 (Fig. 1). The results were concurred with our previous findings, illustrating that high seed $\mathrm{Cd}$-accumulating cultivars have higher $\mathrm{Cd}$ concentrations in shoots of seedlings and vice versa $[3,5]$.

The root-to-shoot Cd translocation in plants is mainly influenced by several processes, including cell wall adsorption, influx into root cells via the plasma membrane, vacuolar sequestration and xylem loading $[9,10]$. Unexpectedly, our results showed that Silihong (high Cd-accumulating cultivar) exhibit higher Cd accumulation in root CWs than Fenghua 1 (low Cd-accumulating cultivar) (Fig. 2). Similar results have been reported by Wang et al. [25] in two contrasting soybean cultivars (HX3 and BX). These findings have refuted our hypothesis that cell wall adsorption might contribute to the difference of $\mathrm{Cd}$ accumulation and translocation between Fenghua 1 and Silihong.

Thus, the difference of $\mathrm{Cd}$ accumulation between Fenghua 1 and Silihong might be determined by transporter mediated processes. In the current study, 30 DEPs were identified to be involved in heavy metal transport (Table 2). Among them, 20 heavy metal transporters were found to be Cd-responsive DEPs in Silihong, including 15 up-regulated proteins and 5 down-regulated proteins. In contrast, only two heavy metal transporters were identified to be DEPs in Fenghua 1.

Some members ABC transporters have been verified to be involved in the uptake and translocation of $\mathrm{Cd}$ in plants [26]. In this study, eight $\mathrm{ABC}$ transporters (ABCB11, ABCB25, ABCC2, ABCC4, ABCC14, ABCG8-like, ABCF1, ABCF3) were found to be induced by $\mathrm{Cd}$ in Silihong, while in Fenghua 1 only one $\mathrm{ABC}$ transporters
(ABCG8) was induced. Moreover, four ABC transporters (ABCB11, ABCB25, ABCC14 and PDR1) showed higher expressions in Silihong than in Fenghua 1 (Table 2).

ABCB25 of peanuts is homologous with AtABCB27/ AtALS1 in Arabidopsis, which is a vacuolar membrane localized transporter in vasculature of the root tip and possibly involved in aluminum vacuolar sequestration [27]. ABCC14 is highly homologous to AtABCC14/ AtMRP10 (71\% identity) and AtABCC4/AtMRP4 (68\% identity). AtABCC2 was firstly identified as a vacuolar-localized transporter of PC-As complexes in Arabidopsis, and it has been shown to play a role in $\mathrm{Cd}$ (and $\mathrm{Hg}$ ) tolerance by sequestrating $\mathrm{Cd}$ in root vacuoles [28]. AtABCC4 was shown to complement yeast $\Delta y c f 1$ mutant for its $\mathrm{Cd}$ hypersensitivity, partially restoring $\mathrm{Cd}$ tolerance [29]. PDR1 (XP_015937455.1) is orthologous to AtPDR12/ABCG40, which is a plasma membrane transporter that functions as an efflux pump for $\mathrm{Pb}^{2+}$ exclusion in Arabidopsis [30]. In cucumber, CsPDR12/ CsABCG40 was up-regulated under Cd stress [31]. Thus, the up-regulation of these transporters by $\mathrm{Cd}$ exposure in Silihong might enhance Cd detoxification by increasing its vacuolar sequestration or efflux from symplast to apoplast.

MTPs have been reported to mediate $\mathrm{Zn} / \mathrm{Cd}$ uptake and translocation [32]. In this study, we found that MTP2 were down-accumulated in Cd-exposed plants of Silihong. Moreover, MTPc2 and MTPc4 were also detected to be higher in Silihong than in Fenghua 1. Peanut MTPc2 is homology with AtMTPc2/AtMTP5 in Arabidopsis, which was reported to form a heteromeric complex with AtMTP12 to transport Zn into the Golgi apparatus [32]. MTP2 and MTPc4 are homology with AtMTP6 and AtMTPc4/AtMTP7 in Arabidopsis, respectively. Nevertheless, characterization of both proteins was not analyzed. Whether these MTPs associate with $\mathrm{Cd}$ uptake and translocation in peanut plants or not require further studies.

The V-ATPase a tonoplast-localized proton pump that provides energy for ion transport. It is a multiheteromeric complex of at least 11 different subunits (i.e. atpv A-H, atpv a, c and d) [33]. Antiport activity of Cd across the tonoplast requires a proton gradient, which is largely dependent on the activity of the V-ATPase [33]. In the current study, three proteins of two V-ATPase subunits (subunit $\mathrm{H}$ and subunit $\mathrm{d} 2$ ) were induced by $\mathrm{Cd}$ in Silihong (Table 2). These results suggest that V-ATPases may promote $\mathrm{Cd}$ into the endomembrane systems in the roots, and consequently, improving $\mathrm{Cd}$ resistance and reducing root-to-shoot $\mathrm{Cd}$ translocation in peanut plants. Meanwhile, higher abundance of V-ATPase subunit $\mathrm{G}$ and V-ATPase $16 \mathrm{kDa}$ proteolipid subunit isoform X4 may be partially responsible for low $\mathrm{Cd}$ translocation in Fenghua 1. 
It was also observed that two P-type ATPases, $\mathrm{Ca}^{2}$ ${ }^{+}$-ATPase 4 and PAA1, were exclusively induced by $\mathrm{Cd}$ in Silihong, and their abundance was higher in Silihong than in Fenghua 1 under $\mathrm{Cd}$ exposure (Table 2). Peanut $\mathrm{Ca}^{2+}$-ATPase 4 exhibits high sequence similarity to AtECA1, an endoplasmic reticulum (ER)-localized $\mathrm{P}_{2 \mathrm{~A}}$-type ATPase in Arabidopsis that confers to $\mathrm{Ca}^{2}$ ${ }^{+} / \mathrm{Mn}^{2+}$ transport from the cytosol into the ER [34]. PAA1 is a chloroplast-envelope $\mathrm{P}_{\mathrm{IB}}$-ATPase that functions in copper transport in chloroplasts [35]. It is unknown whether $\mathrm{Ca}^{2+}$-ATPase 4 and PAA1 is involved in $\mathrm{Cd}$ transport, however, their up-regulation might improve nutrition of essential nutrients such as $\mathrm{Ca}, \mathrm{Mn}$ and $\mathrm{Cu}$ in Silihong.

In that all abovementioned Cd-responsive transporters could not well explain the difference of $\mathrm{Cd}$ accumulation between Silihong and Fenghua 1, we speculate that the mechanism may be the inherent characteristics. Interestingly, we found that several transporters such as ATX1, ACA8, ZIP1 and V-type proton ATPase subunit D were higher in Silihong than in Fenghua 1 under Cd-free conditions. Moreover, all these transporters were suppressed by $\mathrm{Cd}$ in Silihong, while they were unchanged in Fenghua 1. ATX1 is a $\mathrm{Cu}$ chaperone that delivers $\mathrm{Cu}$ and $\mathrm{Cd}$ to $\mathrm{Ccc} 2$, which is an ER membrane-localized $\mathrm{Cu}$-transporting ATPase [36]. This protein may not be involved in root-to-shoot $\mathrm{Cd}$ transport in plants. ACA8 as a P-type ATPase involved in cation efflux from the cytosol [37], has been described to be a candidate for $\mathrm{Cd}$ accumulation that possiblely move $\mathrm{Cd}$ to the xylem in Noccaea caerulescens [38]. ZIP1 of peanut exhibits high sequence similarity to Arabidopsis AtZIP2. AtZIP2 is expressed in the plasma membrane of root stele cells [12], and it is likely to be involved in $\mathrm{Zn}, \mathrm{Mn}$ and $\mathrm{Cd}$ translocation from roots to shoots [12, 39]. It seems that higher abundance of ACA8 and ZIP1 in the roots of Silihong contributes to its higher capacity for root-to-shoot $\mathrm{Cd}$ translocation.

\section{Cell wall modifying proteins in roots of Fenghua 1 and Silihong}

The CW of roots as the first composition for plants in contact with $\mathrm{Cd}$, play key roles in the prevention of $\mathrm{Cd}$ from entering into the cytoplast $[9,10]$. CWs contain many negatively charged groups such as $-\mathrm{COOH},-\mathrm{OH}$ and $-\mathrm{SH}$, which enable metal cations to bind into CWs effectively [15]. Our proteomic analysis showed that a total of 150 DEPs were involved in the modification of cell walls in the roots of the two peanut cultivars (Additional file 6: Table S5 and Additional file 7: Table S6).

Pectin is mainly responsible for the capacity of CW for the binding of metal cations due to their highly negatively charged carboxylic groups [17]. The accumulation of Al has been reported to positively relate to pectin content but negatively correlate with the degree of methylesterification of pectin in Zea mays [40, 41]. Cd induced increases in low-methylesterified pectin were found in flax hypocotyls [42], basket willow [43] and rice [44]. More interestingly, the hyperaccumulating ecotype of Sedum alfredii was found to show lower pectin content and activity of pectin methylesterase than the non-hyperaccumulating one, leading to a high methylesterified pectins that may be responsible for higher root-to-shoot $\mathrm{Cd}$ translocation of the hyperaccumulating ecotype [15].

In this study, we found that some proteins related to pectin decomposition such as $\beta$-Gal, PG, and PL1 were significantly induced in $\mathrm{Cd}$-exposed Silihong, while in Fenghua 1, they remained unaffected (Additional file 6: Table S5). The results indicate that $\mathrm{Cd}$ might induce a degradation of pectin in the roots of Silihong that may reduce its binding in CWs. Furthermore, higher abundance of PEs, PE8B, PPE61, and PGIP2 in Fenghua 1 (Additional file 6: Table S5) suggests that Fenghua 1 shows a higher capacity for preventing pectin decomposition and methylesterification than Silihong under $\mathrm{Cd}$ exposure. This was proven by the higher uronic acid and total sugar contents in pectin of Fenghua 1, which was accompanied with higher pectin Cd contents, compared with Silihong (Fig. 2a).

Hemicellulose and cellulose are major sites binding metal ions in the cell wall $[18,44]$. In the nonpoalean monocotyledons and dicotyledons, xyloglucan is the major hemicellulose of the primary CW [18]. Our results indicate that most $\mathrm{Cd}$ in the $\mathrm{CW}$ is bound to the hemicelluloses for both cultivars (Fig. 2a). Compared with Fenghua 1, Silihong has higher Cd concentrations in the hemicelluloses ( $\mathrm{HC} 1$ and $\mathrm{HC} 2$ ) and cellulose (Fig. 2a), which is accompanied by a higher total sugar content in hemicelluloses ( $\mathrm{HC} 1$ and $\mathrm{HC} 2$ ) and cellulose (Fig. 2c). Hence, the higher contents of hemicelluloses and cellulose might be responsible for higher $\mathrm{Cd}$ in the $\mathrm{CW}$ of Silihong.

The modification of CWs is catalyzed by several enzymes including XTHs and Expansins. XTHs contribute to cell wall extension either by cutting and relinking xyloglucan chains or by catalyzing the hydrolysis of xyloglucan [18]. Expansins can induce loosening and extension of plant CWs by disrupting non-covalent bonding between cellulose microfibrils and matrix glucans. In the present study, we found that two XTH proteins (XTH1 and $\mathrm{XTH} 23$ ) were induced by $\mathrm{Cd}$ exposure in Fenghua 1, while in Silihong, five proteins (XTH1, XTH2, XTH6, XTH30, and XTH32) and two $\alpha$-expansins (EXPA11 and EXPA8) were induced (Additional file 6: Table S5). Moreover, the total sugar content of the hemicelluloses ( $\mathrm{HC} 1$ and $\mathrm{HC} 2$ ) and cellulose was increased by Cd treatments in Silihong, while they remained unaffected in 
Fenghua 1 (Fig. 2c). These results indicate that XTHs and $\alpha$-expansins might be responsible for $\mathrm{Cd}$ resistance by maintaining $\mathrm{CW}$ extensibility in Silihong under $\mathrm{Cd}$ exposure.

Besides XTHs and Expansins, the CW was also modified by other polysaccharide-degrading enzymes, represented by $\beta$-glucosidase, glycosyltransferase and endo-xylanases. Compared with Fenghua 1, Silihong showed a higher abundance of IRX10L, BGLU12-like, BGLU42, EXLB1, XTH30, XTH6 and XYL7, but a lower abundance of BGLU13-like, endo-1,3;1,4-beta-D-glucanase-like, XLA1 and XLA2 under Cd exposure (Additional file 6: Table S5). IRX10L is a glycosyltransferase that plays a role in elongation of the xylan backbone in the hemicellulose [45]. BGLUs can break down the terminal, non-reducing $\beta$-D-glucosyl residues with release of beta-D-glucose. Endo-1,3-1,4-beta-D-glucanase act on the endohydrolysis of (1-3)- or (1-4)-linkages in $\beta$-D-glucans, whereas XYLs are active on these latter oligomers releasing xylose. XLAs are also needed for the degradation of arabinoxylan in that they act synergistically with endoxylanases and cleave arabinose from the backbone. The results presented here suggest that the two cultivars differ from each other in the modification of CWs under Cd exposure. By contrast, more hemicellulose modifying enzymes were observed to show a higher abundance in Silihong compared with Fenghua 1, indicating that it has a higher capacity for CW remodelling. This might better explain the higher contents of hemicellulose and cellulose in the root of Silihong as indicated by the total sugar (Fig. 2c). It seems that the higher $\mathrm{Cd}$ accumulation in hemicelluloses and cellulose of the root CWs in Silihong might be resulted from its higher capability of CW modification.

Lignin, a phenolic polymer derived from hydroxycinnamyl alcohols, is also a major factor limiting Cd uptake into root cells $[10,46]$. Lignin contains several functional groups such as hydroxyl, phenolic, carboxyl, methoxyl, aldehyde, and benzyl alcohol groups, which is able to bind metals to CWs [47]. Lignin is mainly presented in secondary thickened plant cells, where it is covalently linked to non-cellulosic polysaccharides and provides rigidity and impermeability to CWs [48]. Lignin predominantly derived from three monolignols including p-coumaryl, coniferyl, and sinapyl alcohols, forming p-hydroxyphenyl $(H)$, guaiacyl $(G)$, and syringyl (S) lignin, respectively. These processes were regulated by a large number of enzymes such as PAL, COMT, CAD, CCR, HCT, 4CL, CCoA-OMTs and so on [48].

In the current study, we found that $\mathrm{Cd}$ increases the abundance of CCoA-OMT and CAD6 in the roots of Fenghua 1. Both CCoA-OMT and CAD6 are key enzymes for the synthesis of guaiacyl lignin [48]. In contrast, almost all enzymes related to the synthesis of lignin monolignols were significantly induced by $\mathrm{Cd}$ in Silihong, including PAL3, COMT, CAD1, two CCR1, two HCT, three 4CLs, and three CCoA-OMTs (Additional file 7: Table S6). In comparison with Fenghua 1, Silihong shows higher abundance of CCR2, 4CL2, PAL3, and HCT26, and a lower abundance of CCoA-OMT (Additional file 7: Table S6). These results indicate that $\mathrm{Cd}$ exposure could trigger the lignification of CWs in peanut roots, and this was more pronounced in Silihong than in Fenghua 1. Increased lignin deposition induced by toxic metals also occurs in numerous plant species [47, 49-52]. Therefore, we can speculate that the higher $\mathrm{CW}$ lignification capacity of Silihong might be, at least partially, responsible for its higher $\mathrm{Cd}$ accumulation in CWs.

\section{Conclusions}

This is a first systematic report of roots proteome changes between two peanut cultivars in response to $\mathrm{Cd}$ exposure. Totally, 375, 1762, 1276 and 771 DEPs were identified during $\mathrm{F}_{\mathrm{Cd}} / \mathrm{F}_{\mathrm{CK}}, \mathrm{S}_{\mathrm{Cd}} / \mathrm{S}_{\mathrm{CK}}, \mathrm{F}_{\mathrm{CK}} / \mathrm{S}_{\mathrm{CK}}$ and $\mathrm{F}_{\mathrm{Cd}} / \mathrm{S}_{\mathrm{Cd}}$ comparison, respectively. The two cultivars differed in the molecular mechanisms in response to $\mathrm{Cd}$ exposure. Silihong is more sensitive to $\mathrm{Cd}$ exposure than Fenghua 1 in terms of root proteomics. The up-regulation of $\mathrm{ABCB} 25, \mathrm{ABCC} 14, \mathrm{ABCC} 2, \mathrm{PDR} 1$ and $\mathrm{V}$-ATPases by $\mathrm{Cd}$ exposure in Silihong might enhance vacuolar sequestration of $\mathrm{Cd}$ and its efflux from symplast to apoplast. The higher Cd accumulation in the root CWs in Silihong might be resulted from its higher capability of $\mathrm{CW}$ modification, in which many proteins such as IRX10L, BGLU12-like, BGLU42, EXLB1, XTH30, XTH6, XYL7, PAL3, COMT, CAD1, and CCR1 were involved. Thus, vacuolar sequestration and efflux of $\mathrm{Cd}$ as well as its adsorption in CW might be the principal mechanism of cadmium detoxification in Silihong (Fig. 6). We also confirmed that the higher abundance of ACA8 and ZIP1 in the roots of Silihong contributes to its higher capacity of root-to-shoot $\mathrm{Cd}$ translocation. These findings could provide novel insight for further understanding the molecular regulatory network of $\mathrm{Cd}$ accumulation in peanuts.

\section{Methods}

Plant materials and growth conditions

Based on our previous study [5], two peanut cultivars differing in seed $\mathrm{Cd}$ accumulation, Fenghua 1 (F, low $\mathrm{Cd}$ cultivar) and Silihong (S, high Cd cultivar) were used for this study. Seeds were commercially obtained from the Shandong Institute of Peanuts, Qingdao, China. After sterilized with $1 \%$ sodium hypochlorite for $10 \mathrm{~min}$, seeds were sown in well-washed sand for germination. After emergence, seedlings with uniform size were transplanted into hydroponic pots (six plants per pot) 


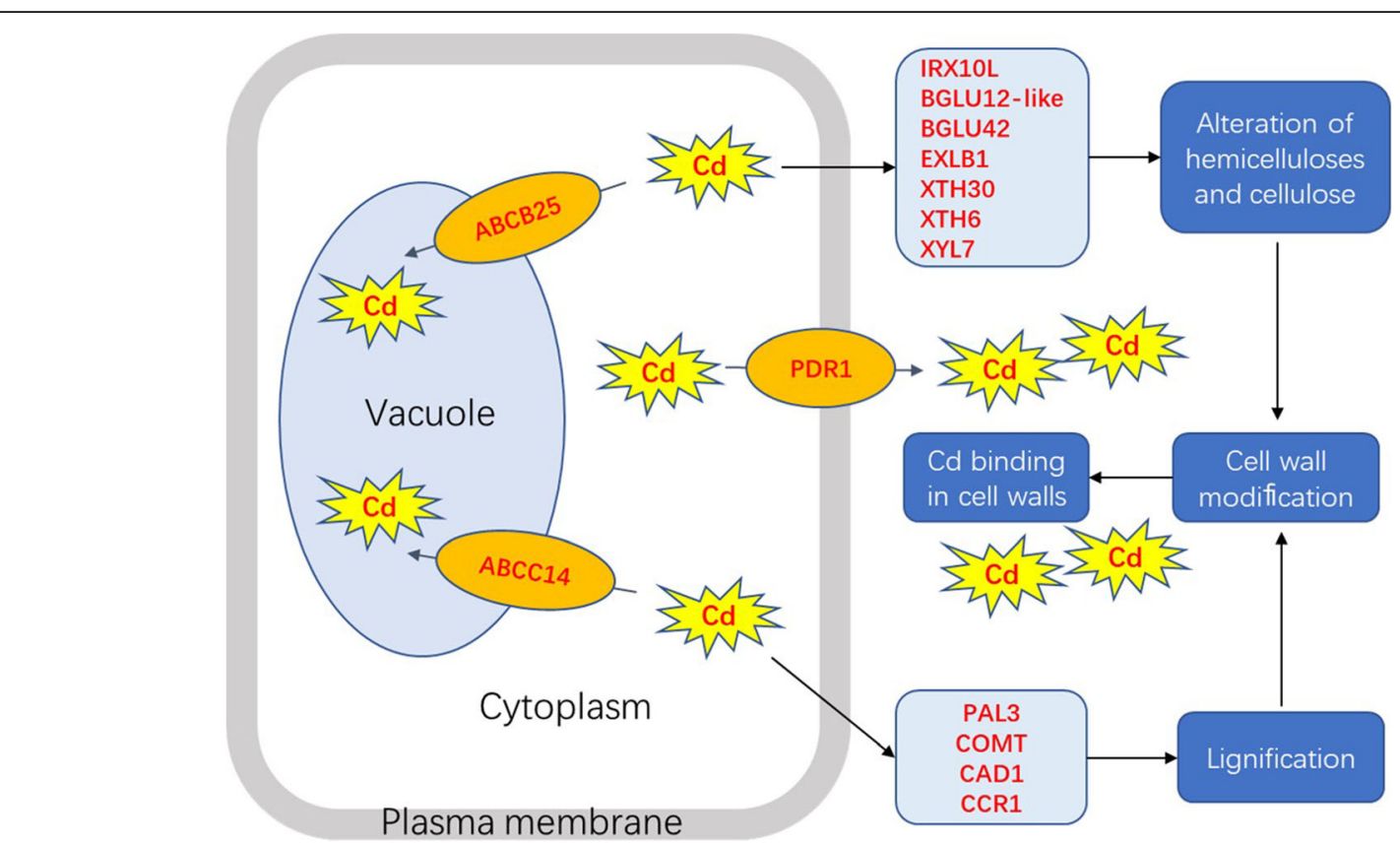

Fig. 6 The putative model of cadmium detoxification in Silihong compared with Fenghua 1. DEPs highlighted with red colour indicate that they were up-regulated by $\mathrm{Cd}$ and showed significantly higher abundance in Silihong compared with Fenghua 1

containing $3.5 \mathrm{~L}$ of Hoagland nutrient solution ( $\mathrm{pH} 5.8$ ) [7]: $5 \mathrm{mM} \mathrm{Ca}\left(\mathrm{NO}_{3}\right)_{2}, 5 \mathrm{mM} \mathrm{KNO}, 1 \mathrm{mM} \mathrm{KH_{2 }} \mathrm{PO}_{4}, 1$ $\mathrm{mM} \mathrm{MgSO}+50 \mathrm{mM} \mathrm{H} \mathrm{H}_{3} \mathrm{BO}_{3}, 4.5 \mathrm{mM} \mathrm{MnCl}, 3.8 \mathrm{mM}$ $\mathrm{ZnSO}_{4}, 0.3 \mathrm{mM} \mathrm{CuSO}_{4}, 0.1 \mathrm{mM}\left(\mathrm{NH}_{4}\right)_{6} \mathrm{Mo}_{7} \mathrm{O}_{24}$ and 50 mM FeEDTA. For determination of $\mathrm{Cd}$ in plant tissues, seven-day-old seedlings were treated with $0,0.2,2$ or $20 \mu \mathrm{M} \mathrm{CdCl} 2$ for 1 week. For other analyses, seven-day-old seedlings were treated with $0(\mathrm{CK})$ and $2 \mu \mathrm{M} \mathrm{CdCl}_{2}$ (Cd) for 1 week. The experiment was arranged using a completely randomized design with three or four replications for each measurement. Plants were grown in a growth chamber as conditions previously described by Lu et al. [7].

\section{Root CW fractionation and measurement}

Root samples (four replicates for each treatment) were collected from 0 (CK) and $2 \mu \mathrm{M} \mathrm{Cd}(\mathrm{Cd})$ for each cultivar. Root samples $(0.5 \mathrm{~g})$ were ground into powder with a mortar and pestle in liquid nitrogen and then homogenized with $7 \mathrm{~mL} 75 \%$ ethanol for $20 \mathrm{~min}$ in an ice-cold water bath. The extracted solutions were centrifuged with $1000 \times \mathrm{g}$ at $4{ }^{\circ} \mathrm{C}$ for $10 \mathrm{~min}$ and the supernatant was removed. The precipitates were extracted twice with 7 $\mathrm{mL}$ of acetone, methanol:chloroform $(1,1)$, and methanol, respectively, for 20 min each. The final crude CWs were freeze dried and weighed.

Fractionation of CW components were performed according to Zhong and Lauchli [53] and Wang et al. [25] with minor modifications. Pectin was extracted twice with $4 \mathrm{~mL} 0.5 \%$ ammonium oxalate buffer (including 1\%
$\left.\mathrm{KHB}_{4}\right)$ in a hot water bath $\left(90-100^{\circ} \mathrm{C}\right)$ for $10 \mathrm{~min}$. The cooled solutions were centrifuged at $17,000 \times \mathrm{g}$ for 10 min and the supernatants containing pectin were pooled together for each sample. The pellets were washed twice with $\mathrm{dd}_{2} \mathrm{O}$ and then, they were further extracted twice with $4 \mathrm{~mL} 4 \% \mathrm{KOH}$ (including $1 \% \mathrm{KHB}_{4}$ ) at room temperature for $12 \mathrm{~h}$. After centrifugation with $17,000 \times \mathrm{g}$ for $10 \mathrm{~min}$, the supernatant containing $\mathrm{HC} 1$ component was collected. Following the same method, HC2 was extracted twice with $4 \mathrm{~mL} 24 \% \mathrm{KOH}$ (including $1 \% \mathrm{KHB}_{4}$ ). Alkaline-insoluble cellulose was dissolved in $72 \%$ sulfuric acid at $25^{\circ} \mathrm{C}$ for $1 \mathrm{~h}$ and then diluted 30 -fold. The $\mathrm{pH}$ of the $\mathrm{HC} 1$ and $\mathrm{HC} 2$ supernatant was adjusted with acetic acid to $6.8-7.2$ so that all the supernatants had the same volume.

The content of total sugar and uronic acid was determined for each fraction as the methods described by Wang et al. [25].

\section{Cd determination}

After 7 days of $\mathrm{Cd}$ treatment, plant roots were immersed in $20 \mathrm{mM} \mathrm{Na} \mathrm{Na}_{2}$-EDTA for $15 \mathrm{~min}$, and then they were rinsed with deionized water three times. Seedlings for each treatments (three replicates) were dissected into roots and shoots. Thereafter, roots and shoots were dried to constant weight at $65^{\circ} \mathrm{C}$. The dried samples were weighed and digested in mixed acid $\left[\mathrm{HNO}_{3}+\right.$ $\left.\mathrm{HClO}_{4}(3: 1, v / v)\right]$. For CW Cd determination, the crude CWs were prepared for each treatment (four replicates) as the method mentioned above [53]. The dried CWs 
were digested with mixed acid $\left[\mathrm{HNO}_{3}+\mathrm{HClO}_{4}(3: 1\right.$, v/ v)] after weighing. $\mathrm{Cd}$ concentrations were determined by atomic absorption spectrometry (WFX-110, Beijing Rayleigh Analytical Instrument Company, China) as previously described [8]. Translocation factors of $\mathrm{Cd}$ from the roots to shoots were calculated as the ratio of $\mathrm{Cd}$ concentrations in shoots to roots.

\section{Protein extraction and quantification}

Root samples for iTRAQ-Seq (two biological replicates) were collected separately from plants treated with 0 (control) and $2 \mu \mathrm{M} \mathrm{Cd}(\mathrm{Cd})$ for each cultivar. A biological replicate contains a pool of six different plants. Approximately $1 \mathrm{~g}$ of each sample was grounded into powder in liquid nitrogen with 10\% PVPP. The powder was transferred into Lysis buffer $(8 \mathrm{M}$ Urea and $40 \mathrm{mM}$ Tris- $\mathrm{HCl}$ containing $1 \mathrm{mM}$ PMSF, $2 \mathrm{mM}$ EDTA and 10 $\mathrm{mM}$ DTT, pH 8.5), and sonicated on ice for $5 \mathrm{~min}$. After centrifugation with $25,000 \mathrm{~g}$ at $4{ }^{\circ} \mathrm{C}$ for $20 \mathrm{~min}$, the supernatant was treated to block the cysteine with 55 mM IAM in a dark room for $45 \mathrm{~min}$. Then the supernatant was treated by adding $5 \times$ volume of $10 \% \mathrm{TCA} /$ acetone with $10 \mathrm{mM}$ DTT to precipitate proteins at $20^{\circ} \mathrm{C}$ for $2 \mathrm{~h}$. After centrifugation with $25,000 \mathrm{~g}$ at $4{ }^{\circ} \mathrm{C}$ for $20 \mathrm{~min}$, the supernatant was discarded and the protein pellet was dried in the air for $5 \mathrm{~min}$. Protein pellets were then dissolved in $200 \mu \mathrm{l} 0.5 \mathrm{M}$ TEAB, followed by centrifugation at $25,000 \mathrm{~g}$ for $20 \mathrm{~min}$. The protein was then quantified using the Bradford method with bovine serum albumin (BSA) as the standard.

\section{Protein digestion, iTRAQ labeling and SCX fractionation}

A total of $100 \mu \mathrm{g}$ proteins for each sample were digested with trypsin gold (Promega, Madison, WI, USA) at 40:1 mass ratio at $37^{\circ} \mathrm{C}$ for $12 \mathrm{~h}$. After digestion, peptides were desalted using Strata X C18 column (Phenomenex) and vacuum-dried following the manufacturer's protocol. The iTRAQ labeling of peptide was processed using iTRAQ reagent 8-plex kit following the manufacturer's instructions. The eight samples including $\mathrm{S}_{\mathrm{Cd} \_} 1, \mathrm{~S}_{\mathrm{Cd} \_}$, $\mathrm{S}_{\mathrm{CK} \_} 1, \mathrm{~S}_{\mathrm{CK} \_} 2, \mathrm{~F}_{\mathrm{Cd} \_} 1, \mathrm{~F}_{\mathrm{Cd} \_} 2, \mathrm{~F}_{\mathrm{CK} \_} 1$ and $\mathrm{F}_{\mathrm{CK} \_} 2$ were labeled with tags 113 and 114, 119, 121, 117, 118, 115 and 116 , respectively, and incubated at room temperature for $2 \mathrm{~h}$. For peptide fractionation, the strong cationic exchange (SCX) chromatography was carried out with a LC-20AB HPLC Pump system (Shimadzu, Kyoto, Japan) with an Ultremex SCX column $(4.6 \times 250 \mathrm{~mm})$ as previously described [54].

\section{LC-ESI-MS/MS analysis}

Each fraction was resuspended in buffer A (2\% acetonitrile, $0.1 \%$ formic acid) and centrifuged at 20,000 rpm for $10 \mathrm{~min}$. $10 \mu \mathrm{L}$ supernatant was loaded on a $2 \mathrm{~cm} \mathrm{C18} \mathrm{trap} \mathrm{column}$ (200 $\mu \mathrm{m}$ inner diameter) and eluted onto a resolving $10 \mathrm{~cm}$ analytical C18 column (75 $\mu \mathrm{m}$ inner diameter) using a LC-20 AD nanoHPLC system (Shimadzu, Kyoto, Japan). The samples were loaded at $15 \mu \mathrm{L} \mathrm{min}^{-1}$ for $4 \mathrm{~min}$. A linear gradient from 2 to $35 \%$ solvent B (98\% acetonitrile, $0.1 \%$ formic acid) was run over $44 \mathrm{~min}$ at $400 \mathrm{~nL} / \mathrm{min}$, and then followed by 2 min linear gradient to $80 \%$, and maintained at $80 \%$ solvent B for $4 \mathrm{~min}$, and finally returned to $2 \%$ in 1 min. Data acquisition was performed with a Triple TOF 5600 System (AB SCIEX, Concord, ON) fitted with a Nanospray III source (AB SCIEX, Concord, ON) and a pulled quartz tip as the emitter (New Objectives, Woburn, MA).

\section{Database search and protein quantification}

The Proteome Discoverer software (Thermo Scientific) was used to convert the raw MS/MS data into MGF format files, which were searched against peanut genome database (ftp://ftp.ncbi.nlm.nih.gov/genomes/Arachis_ duranensis/) using Mascot version 2.3.02 (Matrix Science, London, UK). At least one unique peptide was necessary for identification of a protein. The labeled peptides by isobaric tags for quantification analysis were performed using IQuant software as previously described [55]. To assess the confidence of the peptides, peptide-spectrum matches (PSMs) were pre-filtered at a PSM-level false discovery rate (FDR) of $1 \%$. Thereafter, based on the "simple principle" (parsimony principle), the identified peptide sequences were assembled into a set of confident proteins. To control the rate of false-positive results at the protein level, a protein FDR at $1 \%$, which was based on the selected protein FDR strategy, was estimated after protein inference (protein-level FDR $\leq 0.01$ ). Quantitative protein ratios were weighted and normalized by the median ratio in Mascot. A protein with Bonferroni-corrected $P$-value $<0.05$ and fold changes $>1.2$ or $<0.833$ was considered as being significant differentially expressed in the pairwise comparison.

Gene Ontology (GO) (http://www.geneontology.org) functional annotation of identified proteins were searched against the non-redundant protein database using Blast2GO program (https://www.blast2go.com/). Kyoto Encyclopedia of Genes and Genomes (KEGG) (http://www.genome.jp/kegg/pathway.html) database was adopted to categorize these identified protein species using Blastx/Blastp 2.2.24 software. Then, GO and KEGG pathway enrichment analysis of the DEPs were implemented with a $P$-value $<0.05$.

\section{RT-qPCR analysis}

Total RNA was extracted from three biological replicates of root samples of both peanut cultivars exposed to 0 and $2 \mu \mathrm{M} \mathrm{CdCl}_{2}$ treatments, respectively. Then the first strand cDNA was synthesized by Prime Script $^{\circ}$ RT 
reagent Kit (Takara, Dalian, China). The specific primers for RT-qPCR analysis were designed using Beacon Designer 7.0 software (Premier Biosoft International, USA), and Actin gene was set as the internal standard (Additional file 8: Table S7). RT-qPCR was conducted on an ABI7300 system (Applied Biosystems, Foster City, CA, USA) using SYBR ${ }^{\circ}$ Green Master ROX (Takara) in a $20 \mu \mathrm{l}$ reaction according to the method described by $\mathrm{Yu}$ et al. [56]. All reactions were performed in three technical replicates. Relative expression level was processed with the $2^{-\Delta \Delta C \mathrm{~T}}$ method.

\section{Additional files}

Additional file 1: Figure S1. The repeatability analysis of data obtained from iTRAQ based on CV (coefficient of variation) analysis. (DOCX $644 \mathrm{~kb}$ )

Additional file 2: Table S1. List of Cd-induced differentially expressed proteins in roots of two peanut cultivars. (XLSX $3414 \mathrm{~kb}$ )

Additional file 3: Table S2. Significantly enriched GO terms for the DEPs. With $P$-value $<0.05$ as cutoff. (XLSX $46 \mathrm{~kb}$ )

Additional file 4: Table S3. Most enriched GO terms for the DEPs. With $P$-value $<0.01$ as cutoff. (XLSX $22 \mathrm{~kb}$ )

Additional file 5: Table S4. Differentially expressed proteins related to ion transporters. (XLSX $27 \mathrm{~kb}$ )

Additional file 6: Table S5. Differentially expressed proteins involved in cell wall metabolism in two peanut cultivars. (XLSX $21 \mathrm{~kb}$ )

Additional file 7: Table S6. Differentially expressed proteins involved in lignin biosynthesis. (XLSX $16 \mathrm{~kb})$

Additional file 8: Table S7. The primers used in RT-qPCR analysis. (XLSX $11 \mathrm{~kb})$

\section{Abbreviations}

4CL: 4-coumarate-CoA ligase; ABC: ATP-binding cassette transporter protein; CAD: Cinnamyl alcohol dehydrogenase; CCOA-OMT: Caffeoyl-CoA Omethyltransferase; CCR: Cinnamoyl-CoA reductase; Cd: Cadmium; DEP: Differentially expressed protein; GO: Gene ontology; KEGG: Kyoto encyclopedia of genes and genomes; MTP: Metal tolerance protein; Nramp: Natural resistance-associated macrophage protein; OPT: Oligopeptide transporter; PDR: Pleiotropic drug resistance-type $A B C$ transporter protein; PE: Pectinesterase; RT-qPCR: Reverse-transcription quantitative PCR; ZIP: Zincregulated transporter//ron-regulated transporter-like Protein

\section{Acknowledgements}

Not applicable.

\section{Funding}

This work was supported by grants from the Natural Science Foundation of China (No. 31671599) and the Innovation Team of Scientific Research Platform of Anhui Province (No. KJ2015TD001). The funding body had no role in the design of the study; in the collection, analyses, or interpretation of data; in the writing of the manuscript, and in the decision to publish the results.

\section{Availability of data and materials}

The mass spectrometry proteomics data have been deposited to the ProteomeXchange Consortium with the dataset identifier PXD012670 (https:/www.ebi.ac.uk/pride/archive/projects/PXD012670).

\section{Authors' contributions}

SG designed the experiments. XC, JQ, LL and BS performed the peanut cultivation. YR performed the sample collection. SG, YR, XC, JQ, LL and BS performed the experiments. SG and YR analysed and interpreted data. SG and $Y R$ wrote and revised the manuscript. All authors read and approved the final manuscript.
Ethics approval and consent to participate

Not applicable.

\section{Consent for publication \\ Not applicable.}

\section{Competing interests}

The authors declare that they have no competing interests for this research.

\section{Publisher's Note}

Springer Nature remains neutral with regard to jurisdictional claims in published maps and institutional affiliations.

Received: 11 February 2019 Accepted: 24 March 2019

Published online: 11 April 2019

\section{References}

1. Shi G, Cai Q. Cadmium tolerance and accumulation in eight potential energy crops. Biotechnol Adv. 2009;27(5):555-61.

2. Liu L, Li W, Song W, Guo M. Remediation techniques for heavy metalcontaminated soils: principles and applicability. Sci Total Environ. 2018;633: 206-19.

3. Shi G, Su G, Lu Z, Liu C, Wang X. Relationship between biomass, seed components and seed $\mathrm{Cd}$ concentration in various peanut (Arachis hypogaea L.) cultivars grown on Cd-contaminated soils. Ecotoxicol Environ Saf. 2014:110:174-81.

4. Su Y, Wang X, Liu C, Shi G. Variation in cadmium accumulation and translocation among peanut cultivars as affected by iron deficiency. Plant Soil. 2013;363(1-2):201-13.

5. Liu C, Yu R, Shi G. Effects of drought on the accumulation and redistribution of cadmium in peanuts at different developmental stages. Arch Agr Soil Sci. 2016;63(8):1049-57.

6. Su G, Li F, Lin J, Liu C, Shi G. Peanut as a potential crop for bioenergy production via Cd-phytoextraction: a life-cycle pot experiment. Plant Soil. 2013:365(1):337-45.

7. Lu Z, Zhang Z, Su Y, Liu C, Shi G. Cultivar variation in morphological response of peanut roots to cadmium stress and its relation to cadmium accumulation. Ecotoxicol Environ Saf. 2013;91(4):147-55.

8. Su Y, Liu J, Lu Z, Wang X, Zhang Z, Shi G. Effects of iron deficiency on subcellular distribution and chemical forms of cadmium in peanut roots in relation to its translocation. Environ Exp Bot. 2014;97(1):40-8.

9. Lux A, Martinka M, Vaculík M, White PJ. Root responses to cadmium in the rhizosphere: a review. J Exp Bot. 2011;62(1):21-37.

10. Loix C, Huybrechts M, Vangronsveld J, Gielen M, Keunen E, Cuypers A. Reciprocal interactions between cadmium-induced cell wall responses and oxidative stress in plants. Front Plant Sci. 2017;8.

11. Takahashi R, Ishimaru Y, Senoura T, Shimo H, Ishikawa S, Arao T, Nakanishi H, Nishizawa NK. The OsNRAMP1 iron transporter is involved in $\mathrm{Cd}$ accumulation in rice. J Exp Bot. 2011;62(14):4843-50.

12. Milner MJ, Seamon J, Craft E, Kochian LV. Transport properties of members of the ZIP family in plants and their role in $\mathrm{Zn}$ and $\mathrm{Mn}$ homeostasis. J Exp Bot. 2013;64(1):369-81.

13. Takahashi R, Ishimaru Y, Shimo H, Ogo Y, Senoura T, Nishizawa NK, Nakanishi H. The OsHMA2 transporter is involved in root-to-shoot translocation of $\mathrm{Zn}$ and $\mathrm{Cd}$ in rice. Plant Cell Environ. 2012;35(11):1948-57.

14. Verret F, Gravot A, Auroy P, Leonhardt N, David P, Nussaume L, Vavasseur A, Richaud P. Overexpression of AtHMA4 enhances root-toshoot translocation of zinc and cadmium and plant metal tolerance. FEBS Lett. 2004:576(3):306-12

15. Li T, Tao Q, Shohag MJI, Yang X, Sparks DL, Liang Y. Root cell wall polysaccharides are involved in cadmium hyperaccumulation in Sedum alfredii. Plant Soil. 2015;389(1):387-99.

16. Sun $Y$, Hui YE, Wei Z, Kong $X$, Qi-Tang WU, Sun Y, Hui YE, Wei Z, Kong $X$, QiTang WU. Root cell wall and phytochelatins in low-cadmium cultivar of Brassica parachinensis. Pedosphere. 2017; https://doi.org/10.1016/S10020160(17)60452-1.

17. Yang XY, Zeng ZH, Yan JY, Fan W, Bian HW, Zhu MY, Yang JL, Zheng SJ. Association of specific pectin methylesterases with Al-induced root elongation inhibition in rice. Physiol Plant. 2013;148(4):502-11.

18. Zhu XF, Shi YZ, Lei GJ, Fry SC, Zhang BC, Zhou YH, Braam J, Jiang T, Xu XY, Mao CZ. XTH31, encoding an in vitro XEH/XET-active enzyme, regulates 
aluminum sensitivity by modulating in vivo XET action, cell wall xyloglucan content, and aluminum binding capacity in Arabidopsis. Plant Cell. 2012; 24(11):4731-47.

19. Nocito FF, Lancilli C, Dendena B, Lucchini G, Sacchi GA. Cadmium retention in rice roots is influenced by cadmium availability, chelation and translocation. Plant Cell Environ. 2011;34(6):994-1008.

20. He $\subset$, Zhou YH, Huang YY, Fu HL, Wang XS, Gong FY, Tan X, Yang ZY. Different proteomic processes related to the cultivar-dependent cadmium accumulation of Amaranthus gangeticus. J Agr Food Chem. 2018;66(5):1085-95.

21. Zhang Z, Zhou H, Yu Q, Li Y, Mendoza-Cózatl DG, Qiu B, Liu P, Chen Q. Quantitative proteomics investigation of leaves from two Sedum alfredii (Crassulaceae) populations that differ in cadmium accumulation. Proteomics. 2017;17(10). https://doi.org/10.1002/pmic.201600456.

22. Xue D, Jiang $H$, Deng $X$, Zhang $X$, Wang $H, X u X$, Hu J, Zeng D, Guo L, Qian Q. Comparative proteomic analysis provides new insights into cadmium accumulation in rice grain under cadmium stress. J Hazard Mater. 2014;280: 269-78

23. Hossain Z, Hajika M, Komatsu S. Comparative proteome analysis of high and low cadmium accumulating soybeans under cadmium stress. Amino Acids. 2012;43(6):2393-416

24. Katam R, Sakata K, Suravajhala P, Pechan T, Kambiranda DM, Naik KS, Guo B, Basha SM. Comparative leaf proteomics of drought-tolerant and -susceptible peanut in response to water stress. J Proteome. 2016;143:209-26.

25. Wang $P$, Yang B, Wan $H$, Fang $X$, Yang $C$. The differences of cell wall in roots between two contrasting soybean cultivars exposed to cadmium at young seedlings. Environ Sci Pollut Res. 2018;25(29):29705-14.

26. Briat J-F, Curie C, Gaymard F. Iron utilization and metabolism in plants. Curr Opin Plant Biol. 2007;10(3):276-82.

27. Larsen PB, Cancel J, Rounds M, Ochoa V. Arabidopsis ALS1 encodes a root tip and stele localized half type $A B C$ transporter required for root growth in an aluminum toxic environment. Planta. 2006;225(6):1447-58.

28. Park J, Song WY, Ko D, Eom Y, Hansen TH, Schiller M, Lee TG, Martinoia E, Lee $Y$. The phytochelatin transporters AtABCC1 and AtABCC2 mediate tolerance to cadmium and mercury. Plant J. 2012;69(2):278-88.

29. Klein M, Burla B, Martinoia E. The multidrug resistance-associated protein (MRP/ABCC) subfamily of ATP-binding cassette transporters in plants. FEBS Lett. 2006;580(4):1112-22.

30. Lee $M$, Lee $K$, Lee J, Noh EW, Lee Y. AtPDR12 contributes to lead resistance in Arabidopsis. Plant Physiol. 2005;138(2):827-36.

31. Migocka M, Papierniak A, Rajsz A. Cucumber PDR8/ABCG36 and PDR12/ ABCG40 plasma membrane proteins and their up-regulation under abiotic stresses. Biol Plant. 2017;61(1):115-26.

32. Fujiwara T, Kawachi M, Sato Y, Mori H, Kutsuna N, Hasezawa S, Maeshima M. A high molecular mass zinc transporter MTP12 forms a functional heteromeric complex with MTP5 in the Golgi in Arabidopsis thaliana. FEBS J. 2015;282(10):1965-79.

33. Dietz KJ, Tavakoli N, Kluge C, Mimura T, Sharma SS, Harris GC, Chardonnens AN, Golldack D. Significance of the V-type ATPase for the adaptation to stressful growth conditions and its regulation on the molecular and biochemical level. J Exp Bot. 2001;52(363):1969-80.

34. Wu Z, Liang F, Hong B, Young JC, Sussman MR, Harper JF, Sze H. An endoplasmic reticulum-bound $\mathrm{Ca}^{2+} / \mathrm{Mn}^{2+}$ pump, ECA1, supports plant growth and confers tolerance to $\mathrm{Mn}^{2+}$ stress. Plant Physiol. 2002;130(1):128-37.

35. Frelet-Barrand A, Rivasseau C, Sautron E, Finazzi G, Rolland N, Boutigny S, Seigneurin-Berny D, Pilon M. HMA1 and PAA1, two chloroplast-envelope PIB-ATPases, play distinct roles in chloroplast copper homeostasis. J Exp Bot. 2014;65(6):1529-40.

36. Heo D-H, Baek I-J, Kang H-J, Kim J-H, Chang M, Kang C-M, Yun C-W. $\mathrm{Cd}^{2+}$ binds to Atx1 and affects the physical interaction between Atx 1 and Ccc2 in Saccharomyces cerevisiae. Biotechnol Lett. 2012;34(2):303-7.

37. Bonza MC, De Michelis MI. The plant $\mathrm{Ca}^{2+}$-ATPase repertoire: biochemical features and physiological functions. Plant Biol. 2011;13(3): 421-30.

38. Halimaa $\mathrm{P}$, Lin $\mathrm{Y}-\mathrm{F}$, Ahonen VH, Blande D, Clemens S, Gyenesei A, Häikiö E, Kärenlampi SO, Laiho A, Aarts MGM, et al. Gene expression differences between Noccaea caerulescens ecotypes help to identify candidate genes for metal phytoremediation. Environ Sci Technol. 2014; 48(6):3344-53

39. Grotz N, Fox T, Connolly E, Park W, Guerinot ML, Eide D. Identification of a family of zinc transporter genes from Arabidopsis that respond to zinc deficiency. Proc Natl Acad Sci U S A. 1998;95(12):7220-4.
40. Schmohl N, Horst WJ. Cell wall pectin content modulates aluminium sensitivity of Zea mays (L.) cells grown in suspension culture. Plant Cell Environ. 2000;23(7):735-42.

41. Eticha D, Stass A, Horst WJ. Cell-wall pectin and its degree of methylation in the maize root-apex: significance for genotypic differences in aluminium resistance. Plant Cell Environ. 2005;28(11):1410-20.

42. Douchiche O, Rihouey C, Schaumann A, Driouich A, Morvan C. Cadmiuminduced alterations of the structural features of pectins in flax hypocotyl. Planta. 2006:225(5):1301-12.

43. Vollenweider P, Cosio C, Günthardt-Goerg MS, Keller C. Localization and effects of cadmium in leaves of a cadmium-tolerant willow (Salix viminalis L. ): part II microlocalization and cellular effects of cadmium. Environ Exp Bot. 2006:58(1):25-40.

44. Xiong J, Lu H, Lu K, Duan Y, An L, Zhu C. Cadmium decreases crown root number by decreasing endogenous nitric oxide, which is indispensable for crown root primordia initiation in rice seedlings. Planta. 2009;230(4):599610.

45. Brown DM, Zhang Z, Stephens E, Dupree P, Turner SR. Characterization of IRX10 and IRX10-like reveals an essential role in glucuronoxylan biosynthesis in Arabidopsis. Plant J. 2009;57(4):732-46.

46. Parrotta L, Guerriero G, Sergeant K, Cai G, Hausman JF. Target or barrier? The cell wall of early- and later-diverging plants vs cadmium toxicity: differences in the response mechanisms. Front Plant Sci. 2015;6(133):133.

47. Xia Y, Liu J, Wang Y, Zhang X, Shen Z, Hu Z. Ectopic expression of Vicia sativa Caffeoyl-CoA O-methyltransferase (VsCCOAOMT) increases the uptake and tolerance of cadmium in Arabidopsis. Environ Exp Bot. 2018;145:47-53.

48. Raes J, Rohde A, Christensen JH, Van de Peer Y, Boerjan W. Genome-wide characterization of the lignification toolbox in Arabidopsis. Plant Physiol. 2003;133(3):1051-71

49. Rui H, Chen C, Zhang X, Shen Z, Zhang F. Cd-induced oxidative stress and lignification in the roots of two Vicia sativa $\mathrm{L}$. varieties with different $\mathrm{cd}$ tolerances. J Hazard Mater. 2016;301:304-13.

50. Elobeid M, Göbel C, Feussner I, Polle A. Cadmium interferes with auxin physiology and lignification in poplar. J Exp Bot. 2012;63(3):1413-21.

51. Kováčik J, Klejdus B. Dynamics of phenolic acids and lignin accumulation in metal-treated Matricaria chamomilla roots. Plant Cell Rep. 2008;27(3):605-15.

52. Yang Y-J, Cheng L-M, Liu Z-H. Rapid effect of cadmium on lignin biosynthesis in soybean roots. Plant Sci. 2007;172(3):632-9.

53. Zhong $\mathrm{H}$, Lauchli A. Changes of cell wall composition and polymer size in primary roots of cotton seedlings under high salinity. J Exp Bot. 1993;44(4): 773-8.

54. Chu P, Yan GX, Yang Q, Zhai LN, Zhang C, Zhang FQ, Guan RZ. iTRAQ-based quantitative proteomics analysis of Brassica napus leaves reveals pathways associated with chlorophyll deficiency. J Proteome. 2015;113:244-59.

55. Li M, Huo X, Pan Y, Cai H, Dai Y, Xu X. Proteomic evaluation of human umbilical cord tissue exposed to polybrominated diphenyl ethers in an ewaste recycling area. Environ Int. 2017;111:362-71.

56. Yu R, Li D, Du X, Xia S, Liu C, Shi G. Comparative transcriptome analysis reveals key cadmium transport-related genes in roots of two pak choi (Brassica rapa L. ssp. chinensis) cultivars. BMC Genom. 2017:18(1):587.

Ready to submit your research? Choose BMC and benefit from:

- fast, convenient online submission

- thorough peer review by experienced researchers in your field

- rapid publication on acceptance

- support for research data, including large and complex data types

- gold Open Access which fosters wider collaboration and increased citations

- maximum visibility for your research: over $100 \mathrm{M}$ website views per year

At $\mathrm{BMC}$, research is always in progress.

Learn more biomedcentral.com/submission 